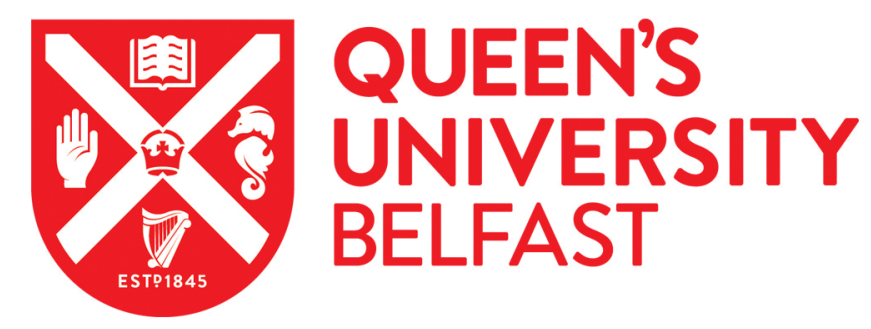

\title{
An Experimentally Validated Numerical Method for Investigating the Air Blast Response of Basalt Composite Plates
}

\author{
Süsler, S., Kurtaran, H., Türkmen, H. S., Kazancı, Z., \& Lopresto, V. (2020). An Experimentally Validated \\ Numerical Method for Investigating the Air Blast Response of Basalt Composite Plates. Mechanics of Advanced \\ Materials and Structures, 27(6), 441-454. https://doi.org/10.1080/15376494.2018.1478049
}

Published in:

Mechanics of Advanced Materials and Structures

\section{Document Version:}

Peer reviewed version

Queen's University Belfast - Research Portal:

Link to publication record in Queen's University Belfast Research Portal

Publisher rights

(c) 2018 Taylor \& Francis Group, LLC. This work is made available online in accordance with the publisher's policies. Please refer to any applicable terms of use of the publisher.

\section{General rights}

Copyright for the publications made accessible via the Queen's University Belfast Research Portal is retained by the author(s) and / or other copyright owners and it is a condition of accessing these publications that users recognise and abide by the legal requirements associated with these rights.

Take down policy

The Research Portal is Queen's institutional repository that provides access to Queen's research output. Every effort has been made to ensure that content in the Research Portal does not infringe any person's rights, or applicable UK laws. If you discover content in the Research Portal that you believe breaches copyright or violates any law, please contact openaccess@qub.ac.uk. 
An Experimentally Validated Numerical Method for Investigating the Air Blast

Response of Basalt Composite Plates

Sedat Süsler ${ }^{1, *}$, Hasan Kurtaran ${ }^{2}$, Halit S. Türkmen ${ }^{3}$, Zafer Kazanc1 ${ }^{4}$, Valentina Lopresto ${ }^{5}$ ${ }^{1}$ Faculty of Aeronautics and Astronautics,

Kocaeli University,

Kartepe, Kocaeli, 41285, Turkey

${ }^{2}$ Department of Mechanical Engineering,

Adana Science and Technology University,

Adana, Turkey

${ }^{3}$ Faculty of Aeronautics and Astronautics,

Istanbul Technical University,

Maslak, Istanbul, 34469, Turkey

${ }^{4}$ Advanced Composites Research Group,

School of Mechanical and Aerospace Engineering,

Queen's University Belfast,

Belfast, BT9 5AH, United Kingdom

${ }^{5}$ Department of Chemical, Materials and Industrial Production Engineering

University of Naples Federico II,

Naples, 80125, Italy

*Corresponding author, Tel: +90-262-3513310 Ext 310, Fax: +90-262-3513311, Email:

sedat.susler@kocaeli.edu.tr

\section{Abstract}

Nonlinear air blast response of basalt composite plates is analysed by using a generalized differential quadrature (GDQ) method, which requires less solution time and decreases the complexity compared to finite element method. A test environment that contains a shock tube is designed and set to experiment on the transient response of blast loaded laminated plates. Experimental and numerical results show a good agreement in terms of displacement, strain and acceleration versus time. The responses of glass/epoxy, Kevlar/epoxy and carbon/epoxy composite plates are also investigated by using GDQ method and the results are compared with the basalt/epoxy composite plate and discussed. 
Keywords: basalt, experimental mechanics, laminated composite plate, first-order shear deformation, computational modelling, blast load, dynamic response, generalized differential quadrature, large deflection, shock tube

\section{Introduction}

Composite materials are widely used in aerospace, marine, automotive and other industries due to desired mechanical properties such as high strength-to-weight ratio. However, analysis of the mechanical behaviour of composite materials is more complex than other materials because of the anisotropic nature of the composites $[1,2]$. The composite materials mainly have two components called reinforcement and matrix. The most common reinforcement types are fibers. One of the newcomers used for the fabrication of the advanced composite materials is basalt fiber. Basalt is a natural inert material produced naturally from the volcanic rocks. Composites reinforced with basalt fibers have prominent properties over the other composites. Compared to carbon and aramid fiber, basalt fiber has the features of wider application temperature range $\left(-269^{\circ} \mathrm{C}\right.$ to $+650{ }^{\circ} \mathrm{C}$ ), higher oxidation resistance, higher radiation resistance, higher compression strength, and higher shear strength. Moreover, $17.5 \%$ better elastic modulus than fiberglass, considered as "green" recyclable, non-respirable and safer even in the factory, no UV treatments are needed, do not harbor mold or mildew or bacteria, ten times better electrical insulator than fiberglass with high temperature strength. It will not ignite easily with the right resins. Basalt composites with better impact strength do not shatter like carbon fibers and are great at blast mitigation $[3,4]$. They also protect from nuclear radiation and does not conduct electricity or interfere with RF signals or MRI waves. Although basalt fibers have good mechanical performance, in particular at high temperature, and its possible applications has not been investigated completely yet. 
Moreover, new basalt fiber composite applications could be widely used in near future due to the potential low cost of this material [5].

The physical and mechanical properties of the basalt fiber reinforced plastics (BFRP) are studied many times in the literature [6-7]. However, their dynamic response is not investigated in detail. The laminated composite plates could be subjected to shock loads during supersonic and hypersonic flights and because of the explosions either in the atmosphere or under the water. The explosive blast effect can be also occurred on blast walls which are sheets or panels on the buildings or the other structures. They protect the buildings, structures and the people from the effects of shock waves of a bomb attack as a barrier. Therefore, basalt fiber reinforced composites, as an alternative material with superior material properties, and their dynamic behaviour prediction under blast loads is an important design consideration.

Finite element method (FEM) and finite difference method (FDM) are commonly used numerical methods to analyse composite and other structures [8-10]. These methods usually require costly calculations in structural analyses. As an efficient alternative method, differential quadrature method (DQM) was introduced by Bellman et al. [11] to achieve acceptable level of accuracy using less grid points. Shu [12] improved DQM by introducing simple explicit formula for the weight coefficients leading to generalized differential quadrature (GDQ) method. Early applications of GDQ method were limited to regular domain problems. Recently, various effective and improved forms of GDQ method are available for complex domains [13-20].

GDQ method and its further improved forms were used to analyse thermo-mechanical, bending, buckling, vibration and transient response of plate and shell structures [21-26]. In transient applications of GDQ method, Civalek [27] predicted nonlinear dynamic 
response of thin isotropic plates by coupling discrete singular convolution (DSC) using harmonic differential quadrature (HDQ) methods. Maleki et al. [28] employed GDQ method to analyse linear transient behaviour of laminated composite plates under different loadings and boundary conditions. Hong [29] used GDQ method to calculate thermal stresses and center displacement in laminated magnetostrictive plates. Peng et al. [30] employed semi-analytic perturbation differential quadrature method to investigate geometrically nonlinear vibration of circular plates. Civalek [31] analysed geometrically nonlinear dynamic response of thin doubly curved isotropic shells resting on elastic foundation by a combination of HDQ and FDM.

There are also several studies on laminated composite plates subjected to blast load. To name a few, Kazanc1 [32] reviewed many papers on blast loaded laminated composite plates including solution theories, numerical methods and various types of timedependent external blast pulse models. Kazancı and Mecitoğlu investigated damped vibrations of a clamped laminated plate [33] and undamped vibrations of simply supported laminated plates [34] under blast loading. Upadhyay et al. [35] analysed nonlinear dynamic response of laminated composite plates subjected to different pulse loadings by using third order shear deformation plate theory. Kazanc1 [36] summarized computational methods to predict the nonlinear dynamic response of laminated flat and tapered composite plates subjected to blast load. Türkmen and Mecitoğlu [37] investigated the structural response of a stiffened laminated composite plate subjected to blast load experimentally. Baştürk et al. [3] studied an analytical model for predicting the deflection of laminated basalt composite plates under several dynamic loads using FDM. Baştürk et al. [4] also investigated the damping effects for a hybrid laminated composite plate subjected to blast load. Susler et al. [38] focused on nonlinear dynamic behaviour 
of laminated plates with linear variable thickness subjected to blast load using Classical Lamination Theory (CLT) and FDM. Duc et al. [39] analysed nonlinear dynamic response and free vibration of functionally graded thick plates subjected to blast load and temperature increment using higher order shear deformation theory. In studies about blast loaded laminated plates above, only theoretical results are obtained. Rajamani and Prabhakaran [40] studied the transient response of E-glass reinforced composite plates with and without central circular holes to blast loading theoretically and experimentally and obtained peak dynamic strains. Besides, shock tube setups are generally used in air blast experimental studies instead of blasting explosive chemical materials like TNT to test composite structures like plates and shells. Some of these studies investigated the nonlinear dynamic behaviour of laminated and sandwich composite plates in elastic range $[37,40,41]$. The others focused on damage analysis and blast resistance of different types of composite plates $[42,43]$. There have been no studies that investigate experimentally validated dynamic behaviour of laminated basalt/epoxy plates under the effects of air blast loading.

In this study, GDQ method is applied to predict nonlinear transient response of laminated basalt fiber reinforced composite plates subjected to blast load. First-order shear deformation theory (FSDT) is used to take transverse shear effect into account and von Karman nonlinear strain-displacement relationships are used to consider geometric nonlinearity. Virtual work principle is used to derive the dynamic equation of motion. Partial derivatives in the equation of motion are expressed using GDQ method and time integration is carried out using Newmark average acceleration method. Experimental studies contain manufacturing plates and testing them by setting a test environment that contains an efficient air-driven shock tube. Displacement-time, strain-time and 
acceleration-time histories are obtained by using GDQ method and compared with ANSYS and experimental results. The response of glass/epoxy, Kevlar/epoxy and carbon/epoxy composite plates is also investigated by using GDQ method and the results are compared with the basalt/epoxy composite plate.

\section{Derivation of the quadrature formulations}

\subsection{Constitutive Equations}

The rectangular laminated basalt fabric composite plate with the length $a$, the width $b$ and the thickness $h$ is depicted in Figure 1. $x$ - $y$ plane indicates the mid-plane of plate $(z=0)$ in Figure 1. Displacements at a general point in the plate at any time can be expressed as

$$
\begin{aligned}
& u(x, y, z, t)=u_{0}(x, y, t)+z \theta_{x}(x, y, t) \\
& v(x, y, z, t)=v_{0}(x, y, t)+z \theta_{y}(x, y, t) \\
& w(x, y, z, t)=w_{0}(x, y, t)
\end{aligned}
$$

where $u_{0}, v_{0}, w_{0}$ are mid-plane displacements, $\theta_{x}$ and $\theta_{y}$ are the rotations about $y$ and $x$ axes, respectively. $x$ and $y$ indicate position of any point and $t$ denotes any time considered. In the case of large displacements, von Karman nonlinear strain-displacement relations for moderately thick plates can be obtained as following [2]:

$$
\varepsilon=\left\{\begin{array}{l}
\varepsilon_{x} \\
\varepsilon_{y} \\
\gamma_{x y} \\
\gamma_{y z} \\
\gamma_{z x}
\end{array}\right\}=\left\{\begin{array}{l}
\frac{\partial u_{0}}{\partial x}+\frac{1}{2}\left(\frac{\partial w_{0}}{\partial x}\right)^{2} \\
\frac{\partial v_{0}}{\partial y}+\frac{1}{2}\left(\frac{\partial w_{0}}{\partial y}\right)^{2} \\
\theta_{y}+\frac{\partial w_{0}}{\partial y}+\frac{\partial w_{0}}{\partial x} \frac{\partial w_{0}}{\partial y} \\
\theta_{x}+\frac{\partial w_{0}}{\partial x}
\end{array}\right\}+z\left\{\begin{array}{l}
\frac{\partial \theta_{x}}{\partial x} \\
\frac{\partial \theta_{y}}{\partial y} \\
\frac{\partial \theta_{x}}{\partial y}+\frac{\partial \theta_{y}}{\partial x} \\
0 \\
0
\end{array}\right\}
$$


The constitutive equation for a laminated composite plate can be written in terms of inplane force and moment resultants as

$$
\left.\left\{\begin{array}{l}
N_{x} \\
N_{y} \\
N_{x y} \\
M_{x} \\
M_{y} \\
M_{x y}
\end{array}\right\}=\left[\begin{array}{llllll}
A_{11} & A_{12} & A_{16} & B_{11} & B_{12} & B_{16} \\
A_{12} & A_{22} & A_{26} & B_{12} & B_{22} & B_{26} \\
A_{16} & A_{26} & A_{66} & B_{16} & B_{26} & B_{66} \\
B_{11} & B_{12} & B_{16} & D_{11} & D_{12} & D_{16} \\
B_{12} & B_{22} & B_{26} & D_{12} & D_{22} & D_{26} \\
B_{16} & B_{26} & B_{66} & D_{16} & D_{26} & D_{66}
\end{array}\right] \begin{array}{l}
\frac{\partial u_{0}}{\partial x}+\frac{1}{2}\left(\frac{\partial w_{0}}{\partial x}\right)^{2} \\
\frac{\partial v_{0}}{\partial y}+\frac{1}{2}\left(\frac{\partial w_{0}}{\partial y}\right)^{2} \\
\frac{\partial u_{0}}{\partial y}+\frac{\partial v_{0}}{\partial x}+\frac{\partial w_{0}}{\partial x} \frac{\partial w_{0}}{\partial y} \\
\frac{\partial \theta_{x}}{\partial x} \\
\frac{\partial \theta_{y}}{\partial y} \\
\frac{\partial \theta_{x}}{\partial y}+\frac{\partial \theta_{y}}{\partial x} \\
\partial y
\end{array}\right\}
$$

Laminate constitutive equation for transverse shear in terms of shear force resultants is shown as

$$
\left\{\begin{array}{l}
Q_{y} \\
Q_{x}
\end{array}\right\}=\left[\begin{array}{ll}
A_{44} & A_{45} \\
A_{45} & A_{55}
\end{array}\right]\left\{\begin{array}{l}
\gamma_{y z} \\
\gamma_{z x}
\end{array}\right\}
$$

$A_{i j}, B_{i j}, D_{i j}$ correspond to the extensional, coupling and bending stiffness matrices, respectively. They are calculated in Eqs. (5) and (6).

$$
\begin{aligned}
& \left\{A_{i j}, B_{i j}, D_{i j}\right\}=\sum_{k=1}^{n} \int_{z_{k-1}}^{z_{k}}\left\{1, z, z^{2}\right\} Q_{i j}^{-(k)} d z \quad(i, j=1,2,6) \\
& A_{i j}=\sum_{k=1}^{n} k_{i} k_{j} \int_{z_{k-1}}^{z_{k}} Q_{i j}^{-(k)} d z \quad(i, j=4,5)
\end{aligned}
$$

where $k_{i}^{2}=5 / 6 \quad(i=4,5)$ indicates the shear correction factors. $z_{k-1}$ and $z_{k}$ indicate top and bottom surface coordinates of $k$-th layer in $z$ direction. $Q_{i j}^{-(k)}$ denote transformed stiffness 
coefficients of $k$-th layer. On the other hand, laminate mass inertias are written as Eq. (7) where $\rho^{(k)}$ is the density of the $k$-th layer.

$\left\{I_{0}, I_{1}, I_{2}\right\}=\sum_{k=1}^{n} \int_{z_{k-1}}^{z_{k}}\left\{1, z, z^{2}\right\} \rho^{(k)} d z$

\subsection{Equations of Motion}

In this study, equation of motion for the laminated composite plate is derived through the virtual work principle. Dynamic version of the virtual work principle can be stated in terms of force and moment resultants as well as inertias as below

$$
\begin{aligned}
& \int_{\Omega}\left[N_{x} \delta \varepsilon_{x}^{0}+N_{y} \delta \varepsilon_{y}^{0}+N_{x y} \delta \gamma_{x y}^{0}+M_{x} \delta \varepsilon_{x}^{0}+M_{y} \delta \varepsilon_{y}^{0}+M_{x y} \delta \gamma_{x y}^{0}+Q_{y} \delta \gamma_{y z}^{0}\right. \\
& +Q_{x} \delta \gamma_{z x}^{0}+\left(I_{0} \ddot{u}_{0}+I_{1} \ddot{\theta}_{x}\right) \delta u_{0}+\left(I_{0} \ddot{v}_{0}+I_{1} \ddot{\theta}_{y}\right) \delta v_{0}+I_{0} \ddot{w}_{0} \delta w_{0}+\left(I_{1} \ddot{u}_{0}+I_{2} \ddot{\theta}_{x}\right) \delta \theta_{x} \\
& \left.+\left(I_{1} \ddot{v}_{0}+I_{2} \ddot{\theta}_{y}\right) \delta \theta_{y}\right] d x d y=\int_{\Omega} q \delta w_{0} d x d y
\end{aligned}
$$

where $q$ denotes distributed load acting on the plate. Using the virtual work principle, equation of motion is obtained in matrix form as

$$
\mathbf{M U ̈}+\mathbf{P}=\mathbf{F}
$$

where $\mathbf{M}$ is mass matrix and $\mathbf{F}, \mathbf{P}, \ddot{\mathbf{U}}$ are external force, internal force and acceleration vectors, respectively. Time integration of equation of motion in this study is carried out with implicit Newmark method. In Newmark method, acceleration in Eq. (10) and velocity in Eq. (11) at (n+1)-th time step are expressed as follow

$$
\begin{aligned}
& \ddot{\mathbf{U}}_{n+1}=c_{0}\left(\mathbf{U}_{n+1}-\mathbf{U}_{n}\right)-c_{1} \dot{\mathbf{U}}_{n}-\ddot{\mathbf{U}}_{n} \\
& \dot{\mathbf{U}}_{n+1}=\dot{\mathbf{U}}_{n}+\Delta t \ddot{\mathbf{U}}_{n}+\frac{\Delta t}{2}\left(\dot{\mathbf{U}}_{n+1}-\ddot{\mathbf{U}}_{n}\right)
\end{aligned}
$$

where, $c_{0}=4 / \Delta t^{2}, c_{l}=4 / \Delta t$ and $\mathbf{U}_{\mathrm{n}}$ are the displacements at $n$-th time step. Substituting Eqs. (10) and (11) into Eq. (9) leads to the following algebraic equation 
$c_{0} \mathbf{M} \mathbf{U}_{n+1}+\mathbf{P}_{n+1}=\mathbf{F}_{n+1}+\mathbf{M}\left(c_{0} \mathbf{U}_{n}+c_{1} \dot{\mathbf{U}}_{n}+\ddot{\mathbf{U}}_{n}\right)$

Eq. (12) is nonlinear in terms of unknown displacements $\mathbf{U}_{n+1}$ since internal force $\mathbf{P}_{n+1}$ depends on $\mathbf{U}_{n+1}$. All of the values on the right hand side are known from the solution of this equation at $n$-th time step. Solution of unknown displacements $\mathbf{U}_{n+1}$ requires the use of an iterative approach such as Newton-Raphson method. Iterative form of Eq. (12) can be obtained by linearizing Eq. (12) as

$\mathbf{K}_{n+1}^{i} \Delta \mathbf{U}_{n+1}^{i}=-\mathbf{R}_{n+1}^{i}$

where $\mathbf{K}_{n+1}^{i}$ is referred to as tangent stiffness matrix, $\Delta \mathbf{U}_{n+1}^{i}$ is the displacement increment in the current iteration. $\mathbf{R}_{n+1}$ is the residual force and written as

$$
\mathbf{R}_{n+1}=\mathbf{F}_{n+1}+\mathbf{M}\left(c_{0} \mathbf{U}_{n}+c_{1} \dot{\mathbf{U}}_{n}+\ddot{\mathbf{U}}_{n}\right)-c_{0} \mathbf{M} \mathbf{U}_{n+1}-\mathbf{P}_{n+1}
$$

by using the calculated displacement increment, improved displacement value at $(i+1)$-th iteration is expressed as

$$
\mathbf{U}_{n+1}^{i+1}=\mathbf{U}_{n+1}^{i}+\Delta \mathbf{U}_{n+1}^{i}
$$

Iterative solution procedure is repeated until the error function $\mathbf{R}_{n+1}^{i+1}$ is sufficiently close to zero. Initial acceleration values $\ddot{\mathbf{U}}_{\mathbf{0}}$ which are required to start the Newton-Raphson solution are calculated by using the initial displacements $\mathbf{U}_{\mathbf{0}}$ and velocities $\dot{\mathbf{U}}_{\mathbf{0}}$ at time $t=0$.

\subsection{GDQ Method}

In this study, GDQ method is used in the calculation of derivatives of field variables in strain-displacement relations. Before GDQ method is applied, plate is discretized with grid points as shown in Figure 2 to determine the points where derivatives and field variable values are to be calculated. 
Derivative of a function with respect to a variable at a given discrete point is expressed as a weighted linear sum of the function values at all discrete points in the mesh line [12]. In this method, $r$-th order derivative of a function $f(x)$ with $n$ discrete grid points can be stated as

$\left(\frac{\partial f^{r}(x)}{\partial x^{r}}\right)_{x_{i}}=\sum_{j=1}^{n} C_{i j}^{(r)} f_{j}$

where $x_{i}$ are the discrete points in the variable domain. $f_{j}$ and $C_{i j}{ }^{(r)}$ are the function values at these points and related weighting coefficients. Lagrange polynomial functions are used in determining the weight coefficients $C_{i j}{ }^{(r)}$. Explicit formula for weight coefficients can be written for first-order derivative, i.e. $r=1$, as below

$C_{i j}^{(1)}=\frac{\Phi\left(x_{i}\right)}{\left(x_{i}-x_{j}\right) \Phi\left(x_{j}\right)} \quad(i \neq j)$

where

$\Phi\left(x_{i}\right)=\prod_{j=1}^{n}\left(x_{i}-x_{j}\right) \quad(i \neq j)$

For higher-order derivatives, the following recursive relations are used

$$
\begin{aligned}
& C_{i j}^{(r)}=r\left[C_{i i}^{(r-1)} C_{i j}^{(1)}-\frac{C_{i j}^{(r-1)}}{\left(x_{i}-x_{j}\right)}\right] \quad(i \neq j) \\
& C_{i i}^{(r)}=-\sum_{\substack{j=1 \\
i \neq j}}^{n} C_{i j}^{(r)}
\end{aligned}
$$

Similar to the one dimensional problems, partial derivatives for the two dimensional case are easily expressed with GDQ method. Considering Figure 2 where $n_{x}$ and $n_{y}$ indicate grid numbers in $x$ and $y$ direction respectively, partial derivatives at a point $\left(x_{i}, y_{j}\right)$ can be 
stated as Eqs. (21-23) where $r$ and $s$ denote derivative orders with respect to $x$ and $y$ variables.

$$
\begin{aligned}
& \left(\frac{\partial f^{r}(x, y)}{\partial x^{r}}\right)_{x_{i}, y_{j}}=\sum_{k=1}^{n_{x}} C_{k j}^{(r)} f_{k j} \\
& \left(\frac{\partial f^{s}(x, y)}{\partial y^{s}}\right)_{x_{i}, y_{j}}=\sum_{m=1}^{n_{y}} C_{i m}^{(s)} f_{i m} \\
& \left(\frac{\partial f^{(r+s)}(x, y)}{\partial x^{r} \partial y^{s}}\right)_{x_{i}, y_{j}}=\frac{\partial^{r}}{\partial x^{r}}\left(\frac{\partial^{s} f}{\partial y^{s}}\right)=\sum_{k=1}^{n_{x}} C_{k j}^{(r)} \sum_{m=1}^{n_{y}} C_{i m}^{(s)} f_{k m}
\end{aligned}
$$

Gauss-Lobatto quadrature points are used as grid points in this study. Use of the Lobatto points improves the accuracy of derivatives in GDQ method. It also simplifies the application of boundary conditions by yielding grid points on the boundaries.

\section{Experimental Procedure}

\subsection{Plate Manufacturing and Material Properties}

Laminated basalt fabric reinforced epoxy matrix composite plates are manufactured by resin infusion technology. First, bidirectional $\left(0^{\circ} / 90^{\circ}\right)$ basalt dry fabrics $-200 \mathrm{~g} / \mathrm{m}^{2}$, plain weave (warp 10F/10 mm, weft 10F/10 mm), tex 100, from ZLBM (De) are overlapped on smooth surface. Then, fabrics are impregnated with the mixture of epoxy matrix (Becor I-SX10 + hardener SX10M). After the specimens are covered with the peel ply and then the plastic bag, the curing process starts at room temperature and at a vacuum level of 990 mbar. The process takes for 24 hours for curing as shown in Figure 3.

In addition to fabrication of plates for air blast tests, coupons made of basalt fabric-epoxy with $\left(0^{\circ} / 90^{\circ}\right)$ fiber orientation are manufactured to determine the material properties. These material properties are then used in the analyses achieved by using GDQ method 
and ANSYS. Tension tests with ASTM D638-14 standard [44] and shear tests with ASTM D3518M-13 standard [45] are done by using four proper specimens for each test method. Lastly, the density of the composite is determined by the burn-off technic. Obtained averaged values of material properties and test results are shown in Table 1. $E_{1}$ and $E_{2}$ are Young's modulus, $G_{12}$ is shear modulus, $v_{12}$ is Poisson's ratio and $\rho$ is defined as the density of the material.

The configurations of four different laminated basalt plates which are approximately 400 $\mathrm{mm} \times 400 \mathrm{~mm}$ are listed and numbered in Table 2 . Henceforth, they are respectively defined as Plate 1, Plate 2, Plate 3 and Plate 4. The fiber volume ratio for all configurations is $50 \%$. Two of the plates have eight layers while the other two have sixteen layers. Moreover, plates which have the same number of layer, have different lay-up according to the directions of $\left(0^{\circ} / 90^{\circ}\right)$ basalt dry fabrics while overlapping.

\subsection{Experimental Studies on Blast Load}

The experimental study is achieved in two steps. In the first step, to determine the transient pressure distribution on plates we use a plexiglass plate that has the same length and width with basalt plates. Then, we measure the pressure distribution by performing certain number of air blast tests. Three PCB 111A26 ICP quartz miniature pressure sensors are used for the pressure measurement. These sensors are durable and low budget, but they need a special perforation process for mounting surface. In this mounting process, at least $19 \mathrm{~mm}$ of plate thickness is required and the sensor's manual proposes to counterbore for thicker plates. Therefore, a plexiglass plate with $19 \mathrm{~mm}$ of thickness is used for the air blast pressure measurements. 
Experimental set-up for the air blast tests is shown in Figure 4, schematically. The air is pumped into a pressure tank by a compressor which has a pressure limit of 40 bar. The air pressure in the tank is controlled by using a valve. The connection between the tank and the shock tube is provided by a pressure resistant hose which has a pressure limit of 256 bar. The pressurized air creates a high pressure region in the shock tube behind the polyester film membrane which has the thickness of $0.19 \mathrm{~mm}$ and creates a burst pressure nearly $600 \mathrm{kPa}$ in each test. After the burst, the air blast passes in the low pressure pipe and the outside air and hits the plexiglass plate. IMC C-Series CS-7008-N data acquisition (DAQ) device is used for collecting pressure data with its maximum sampling rate of 100 kHz. The general views of test set-up are shown in Figure 5.

A practical method is used to obtain the pressure data at different locations as many as possible for the plexiglass plate as shown in Figure 6. For the first test, the pressure data is obtained on the first quarter of the model for point $1(\mathrm{P} 1)$, point $2(\mathrm{P} 2)$ and point $3(\mathrm{P} 3)$. Afterwards, the test is repeated for P1 again, point $4(\mathrm{P} 4)$ and point $5(\mathrm{P} 5)$. Then, the plexiglass plate is rotated $90^{\circ}$ for three times and is fixed again for measurement at other points as illustrated in Figure 6. So, the pressure distribution can be obtained by using seventeen locations on the plexiglass plate by drilling only five holes and using only three pressure sensors.

Peak pressure values measured at all other sixteen locations are very close to the pressure value at $\mathrm{P} 1$ which is the center of the $300 \mathrm{~mm} \times 300 \mathrm{~mm}$ plate. The pressure-time histories for all points have also close values to each other for their positive phase duration. These can lead to an assumption of uniform pressure distribution. The magnitudes of peak pressure at $\mathrm{P} 1$ in repeated tests are shown together in Figure 7 and they are close to each other. All peak pressure values range in an interval between $26.9 \mathrm{kPa}$ and $28.9 \mathrm{kPa}$ except 
for the value of first test that has a measured magnitude of $31.19 \mathrm{kPa}$. Therefore, it is accepted that the blast tests performed in this study are repeatable and same pressure value and distribution are obtained in each test.

In the second step, strains and accelerations are measured at two points chosen on the basalt plates subjected to blast load. Since the blast tests are repeatable and same pressure value and distribution are obtained in each test, the pressure is not measured in these tests again. Strain is measured by using $\left(0^{\circ}-90^{\circ}\right)$ rosette type strain gauges which are named as Vishay C2A-06-062LT-350. Brüel\&Kjaer 4516-001 piezoelectric accelerometers are used for measuring acceleration. Accelerometers have a measuring range for the acceleration up to approximately $\pm 11000 \mathrm{~m} / \mathrm{s}^{2}$. DAQ device used for the strain and acceleration measurement is VTI Instruments EX1629 which has a sampling rate of 25 $\mathrm{kHz}$. The distance between the plate and the membrane is one meter as shown in Figure 4. The $400 \mathrm{~mm} \times 400 \mathrm{~mm}$ plates are clamped for all edges with two metallic frames and 36 bolts and nuts. Each steel frame used for clamping the basalt plates has about $7 \mathrm{~mm}$ thickness and $50 \mathrm{~mm}$ width along each edge as shown in Figure 5. This leads to a 300 $\mathrm{mm} \times 300 \mathrm{~mm}$ effective plate area which is going to be used for the input of numerical analyses. The points for strain and acceleration measurement are selected as the center of the whole basalt plate $(a / 2 ; b / 2)$ and center of the quarter of the plate $(a / 4 ; b / 4)$. Strain gauges and accelerometers are also located on top surface of the basalt plates which is depicted in Figure 1. So, they are attached to the back side of the plate and will not be affected harmfully by the air blast wave. The strains and accelerations are measured for a suitable time duration to be able to obtain the first peak.

The pressure distribution on the plate surface is formularized according to combining tests for pressure measurement with the definition of typical blast wave curve in 
Friedlander's waveform which could be defined as a function of time. If the plate is placed distant enough $(>1 \mathrm{~m})$ from the source of the blast, the pressure distribution is assumed to be uniform and subjects in the $z$ direction only. Friedlander's function defines the typical air blast load as shown in Eq. (24). Here, $p_{m}$ is the peak pressure, $t_{p}$ is positive phase duration, and $\varphi$ is a waveform parameter.

$$
p(x, y, t)=P_{m}\left(1-\frac{t}{t_{p}}\right) e^{-\frac{\varphi t}{t_{p}}}
$$

The peak pressure and positive phase duration obtained by using experimental pressure data and they are shown in Table 3. Besides, the waveform parameter of each curve must be calculated by replacing $p_{m}$ and $t_{p}$ in Eq. (24). Then, data points for negative peak pressure are selected in negative phase duration of each curve and they are replaced in Eq. (24), too. Finally, the only unknown, $\varphi$ is calculated for each test and the average of each parameter in Eq. (24) is shown in Table 3.

\section{Results and Discussion}

GDQ, ANSYS finite element software and experimental results are compared and discussed in this section. Thereafter, GDQ method is performed to compare air blast response of basalt fibers with the common types of fibers following verification of the theoretical method with experimental method and ANSYS.

First of all, basalt fiber reinforced laminated composite plates with all edges clamped are modelled using ANSYS finite element software. 28 x 28 eight nodded layered shell elements (Shell281) which have six degrees of freedom at each node are used to discretize the rectangular plates. These shell elements have the capability of geometric nonlinearity and are typically described as geometrically planar elements. As a result of a mesh 
sensitivity analysis, it is found that modelling the blast loaded plate using 784 elements gives enough accuracy. Each lamina is assumed to be perfectly bonded to adjacent two laminae in the finite element model.

The blast load is formularized by using a suitable function as Eq. (24) which is obtained by experimental studies in Table 3. Then, the defined function is introduced to the ANSYS as a pressure force on the whole plate area. The geometrically nonlinear transient analyses are performed to obtain the strain-time and acceleration-time histories for the selected points of the plate. Four different laminated basalt plates (Table 2) which have different stacking sequences are analysed.

A mesh of $9 \times 9$ grids is used in transient analyses using GDQ method in this study. The parameters used for equation of air blast load explained above are $P_{m}=28.45 \mathrm{kPa}$, $t_{p}=0.00089 \mathrm{~s}$ and $\varphi=0.53$ according to Table 3. Damping effect is neglected in GDQ method.

The material properties of a basalt fabric-epoxy layer and basalt plate lay-up configurations used in the numerical analyses achieved by GDQ method and ANSYS are shown in Table 1 and Table 2 . The degree of 0 for plies denotes a $\left(0^{\circ} / 90^{\circ}\right)$ basalt/epoxy layer orientation, while the degree of 45 for plies actually denotes a $\left( \pm 45^{\circ}\right)$ layer orientation in Table 2 because of using bidirectional fabric. The total thickness and number of layers for plates are also shown in Table 2. All four laminated basalt fabric reinforced plates have square shape and the dimensions are taken as $a=b=300 \mathrm{~mm}$.

Before the analysis of plate response, sensitivity analysis is lastly conducted with respect to time step for both GDQ and ANSYS. Figure 8 for GDQ and Figure 9 for ANSYS compare the effect of time step by choosing three different numbers of step. 
Displacement, strain and acceleration data in these figures are normalized and peak values of different time steps are also shown in figures. According to sensitivity analysis and by also concerning the computational cost, a time step of $0.015 \mathrm{~ms}$ for 200 steps which converges closely to time histories of 600 steps is used for GDQ method. Similarly, the number of time step for ANSYS is chosen as $0.020 \mathrm{~ms}$ with 150 steps. It is also noticed that GDQ method converges fast using bigger time step according to the curve and peak values of the maximum and minimum time step. This means less number of time step leads to less solution time.

The displacement-time histories are obtained at point $(a / 2 ; b / 2)$ and point $(a / 4 ; b / 4)$ and are respectively shown for all basalt plates considered in this study in Figures 10-13. In these figures, GDQ results are compared with the ones obtained by ANSYS. There is a good agreement between displacement-time histories of all basalt plate configurations not only for peak values but also for their frequency. On the other hand, the correlation is slightly better for point $(a / 2 ; b / 2)$ when the thickness of the laminated plate is increased. Plate 1 and Plate 3 which have sixteen layers, have smaller peak values than the other two which have eight layers as expected. Layers with $\pm 45^{\circ}$ fiber orientations of bidirectional $\left(0^{\circ} / 90^{\circ}\right)$ basalt fabrics in basalt plates do not seem to have a significant effect on displacement and frequency. Small increase in total thickness of Plate 3 against Plate 1 and Plate 4 against Plate 2 can cause the peak values to be decreased as shown in Table 2.

All compared strain values are in the $x$ direction and can be denoted by the notation $\varepsilon_{x}{ }^{\text {top }}$. Specimens are all square plates, so there is no difference between values of $\varepsilon_{x}{ }^{\text {top }}$ and $\varepsilon_{y}{ }^{\text {top }}$ at a certain point. For the Plate $1, \varepsilon_{x}^{\text {top }}$-time histories are shown at point $(a / 2 ; b / 2)$ in Figure 14 and at point $(a / 4 ; b / 4)$ in Figure 15 . Similarly, $\varepsilon_{x}{ }^{\text {top }}$-time histories at certain points are shown for Plate 2 in Figure 16 and Figure 17, for Plate 3 in Figure 18 and Figure 19 and 
for Plate 4 in Figure 20 and Figure 21. GDQ and ANSYS results are compared with three repeated test results in all figures of $\varepsilon_{x}{ }^{t o p}$-time histories.

Figure 22 and Figure 23 show acceleration-time histories in the $z$ direction for the Plate 1 at point $(a / 2 ; b / 2)$ and point $(a / 4 ; b / 4)$, respectively. GDQ and ANSYS results are compared with three repeated test results and there is a good correlation between the results. It must be also remembered that the accelerometers have a measuring limit for acceleration up to approximately $\pm 11000 \mathrm{~m} / \mathrm{s}^{2}$ while the acceleration-time histories at point $(a / 2 ; b / 2)$ are evaluated in Figure 22. So, some of the data points could be missed in measured accelerations in the test results shown in Figure 22. This situation causes discrepancies between the numerical and experimental results for acceleration levels which are higher than measuring limit as shown in Figure 22. The range of acceleration in Figure 23 is between $+10000 \mathrm{~m} / \mathrm{s}^{2}$ and $-8000 \mathrm{~m} / \mathrm{s}^{2}$, so experimental acceleration data at point $(a / 4 ; b / 4)$ will be in the range of measuring limit. Therefore, a better agreement is found between the numerical and experimental acceleration-time histories for the point $(a / 4 ; b / 4)$ as shown in Figure 23.

To evaluate more on the agreement of GDQ method with ANSYS and experiments, mean absolute percentage error (MAPE) of time histories above are calculated and shown in Table 4. $n=76$ for $3 \mathrm{~ms}$ is used for fitted points of strains which is actually number of time step for tests which is also known sampling rate of data acquisition. $n=150$ for $3 \mathrm{~ms}$ is used for fitted points of displacements which cannot be measured in tests. ANSYS results are defined as the actual values and GDQ results are defined as the forecast values in displacement-time histories for the calculation of MAPE. On the other hand, experimental results are defined as the actual values while GDQ results still remain as the forecast values of MAPE in $\varepsilon_{x}^{\text {top }}$-time histories in Table 4. MAPE of displacement-time histories 
shows that agreement with ANSYS are very good while agreement with experimental results according to MAPE are defined as inconsistent. There are some non-acceptable results while some of MAPE values shows the agreement.

Moreover, first peak values of displacement and $\varepsilon_{x}{ }^{\text {top }}$ are tabulated and compared with percentage error (PE) for all basalt plate configurations at certain points in Table 4. First peak value of a concerned variable is critical for an air blast response, because it is usually the maximum value as a result of the phenomena of damping effect. Obtained experimental strain peak values in Table 4 are averages of three test results. The predicted peak displacement and strain values using GDQ and ANSYS are found to be in a good agreement with the experimental ones. Agreement of displacement-time peaks is more consistent and better than strain-time peaks. GDQ method is more compatible with ANSYS. Agreement of GDQ method with experiments for strain-time peaks is more inconsistent but not as MAPE values. It is acceptable and much better for thinner plates. The dynamic behaviour of air blast loaded glass/epoxy, Kevlar/epoxy and carbon/epoxy composite plates is also analysed by using GDQ method. In these analyses the stacking sequence, fiber orientation angle, thickness and dimensions of the Plate 1 are used to be able to compare with the results of basalt/epoxy. The material properties of glass/epoxy, carbon/epoxy [38] and Kevlar/epoxy [46] are shown in Table 5. The displacement-time histories at point $(a / 2 ; b / 2)$ obtained by using GDQ method are shown in Figure 24. Basalt/epoxy has lower peak displacements than glass/epoxy and Kevlar/epoxy except carbon/epoxy as expected. Figure 25 shows $\varepsilon_{x}{ }^{\text {top }}$-time histories at point $(a / 2 ; b / 2)$ of four different composite materials. Basalt/epoxy has smaller strain peak values except carbon fibers similarly with displacement results. It is also observed that basalt fiber has the lowest acceleration values during the dynamic response as shown in Figure 26. It is also 
shown that the basalt fiber has the lowest response frequency indicating that reaching the peak displacement or strain takes more time compared to the other fibers as shown in Figures 24-25. The lowest acceleration and response frequency of the basalt fiber could be considered as a contributing factor to increase the resistance against air blast.

\section{Conclusions}

Numerical and experimental processes are presented comprehensively to predict the dynamic behaviour of basalt fabric reinforced composite plates under blast load. In the numerical side of the study, GDQ method which requires less solution time by converges fast using bigger time step and decreases the complexity compared to FEM is used. Hence, it may be more preferable or might at least provide a valuable alternative solution for composite structures under blast load.

FSDT is used to take into account transverse shear effect and von Karman nonlinear strain-displacement relationships are used to take into account large deflection effect. Virtual work principle is used to derive the dynamic equations of motion. Additionally, a commercial finite element solver, ANSYS, is also used to model the dynamic behaviour of basalt plates subjected to blast load. GDQ and ANSYS results are compared with experimental results. It is found that there is a good agreement between the FEM, GDQ and experimental results for the dynamic behaviour of blast loaded basalt composite plates which have different stacking sequences and fiber orientations.

In the experimental side of the study, the repeatable blast tests are performed and the pressure and strains are measured in separate tests. This method prevented the basalt plates from the effect of pressure sensors during the strain and acceleration measurement. In the numerical side of the study, a new method including the large deflection and 
transverse shear effects is presented for the prediction of strain and acceleration during the blast loading of basalt plates. The GDQ method, compared to the FEM, requires less solution time and decreases the complexity which may be a good alternative for preliminary design. Moreover, the same accuracy is obtained using fewer grids compared to FEM for the prediction of the dynamic response of plates subjected to blast loading.

Comparison of the basalt fiber blast performance with the familiar types of fibers showed that only carbon fiber has lower peak values of displacement and strain than basalt fiber. Basalt fiber has also the lowest acceleration and response frequency which is indicating the lower damage risk against air blast load compared to the other fiber types. Furthermore, basalt fibers have superior material characteristics in comparison with other three types of fibers like oxidation and radiation resistance, operation temperature range, very low cost and being environment friendly material as mentioned in the Introduction above.

This study aims to be used as a database for the conceptual designs of basalt composite structures which can be modelled as plates such as blast walls or some aviation and marine components. The blast pressure is uniformly distributed on the basalt laminated plates in this study. The plates can be subjected to non-uniform pressure distribution or local transient pressure effects. Besides, linear elastic material conditions are only considered for the basalt plates. The material nonlinearities can be taken into account by also considering damping under the transient loading of very high pressurized air blast waves. These will be the subject of future studies. 


\section{Acknowledgements}

The authors are very grateful to Faculty of Aeronautics and Astronautics at Istanbul Technical University (ITU) for using air blast test set-up and CIRTIBS Research Centre of the University of Naples Federico II for using their manufacturing facilities.

\section{Funding}

The authors received no financial support for the research, authorship and publication of this article.

\section{References}

[1] M.S. Qatu, Vibration of Laminated Shells and Plates, 1st ed. Amsterdam, The Netherlands: Elsevier, 2004.

[2] J.N. Reddy, Mechanics of Laminated Composite Plates and Shells: Theory and Analysis, 2nd ed. USA: CRC Press, 2004.

[3] S. Baştürk, H. Uyanık, and Z. Kazancı, "An analytical model for predicting the deflection of laminated basalt composite plates under dynamic loads," Compos. Struct., vol. 116, pp. 273-285, 2014.

[4] S. Baştürk, H. Uyanık, and Z. Kazancı, "Nonlinear damped vibrations of a hybrid laminated composite plate subjected to blast load," Procedia Eng., vol. 88, pp. 18-25, 2014.

[5] K. Singha, “A short review on basalt fiber,” Int. J. Text. Sci., vol 1, pp. 19-28, 2012.

[6] V. Dhand, G. Mittal, K.Y. Rhee, S.J. Park, and D. Hui, “A short review on basalt fiber reinforced polymer composites," Compos. B Eng., vol 73, pp. 166-180, 2015. 
[7] V. Lopresto, C. Leone, and I. De Iorio, "Mechanical characterisation of basalt fibre reinforced plastic," Compos. B Eng., vol. 42, pp. 717-723, 2011.

[8] R.D. Cook, D.S. Malkus, and M.E. Plesha, Concepts and Applications of Finite Element Analysis, 3rd ed. New York, USA: John Wiley \& Sons, 1989.

[9] K.J. Bathe, Finite Element Procedures in Engineering Analysis, 1st ed. New Jersey, USA: Prentice-Hall, 1982.

[10] S.C. Chapra and R.P. Canale, Numerical Methods for Engineers, 6th ed. New York, USA: McGraw Hill, 2009.

[11] R. Bellman, B.G. Kashef, and J. Casti, "Differential quadrature: A technique for the rapid solution of nonlinear partial differential equations," J. Comput. Phys., vol. 10, pp. 40-52, 1972.

[12] C. Shu, Differential Quadrature and Its Applications in Engineering. 1st ed. UK: Springer-Verlag, 2000.

[13] Y. Xing, B. Liu, and G. Liu, "A differential quadrature finite element method," Int. J. Appl. Mech., vol. 2, pp. 1-20, 2010.

[14] Z. HongZhi and Y. ZhiGuang, "Analysis of thin plates by the weak form quadrature element method," Sci. China Phys. Mech. Astron., vol. 55, pp. 861-871, 2012.

[15] Z. HongZhi, C. Pan, and H. Yu, "Buckling analysis of shear deformable plates using the quadrature element method," Appl. Math. Modell., vol. 35, pp. 5059-5074, 2011.

[16] C.W. Bert and M. Malik, "Differential quadrature method in computational mechanics: A review," Appl. Mech. Rev., vol. 49, pp. 1-28, 1996. 
[17] F. Tornabene, N. Fantuzzi, F. Ubertini, and E. Viola, "Strong formulation finite element method based on differential quadrature: A survey," Appl. Mech. Rev., vol. 67, pp. 020801, 2015.

[18] C.N. Chen, Discrete Element Analysis Methods of Generic Differential Quadratures. 1st ed. The Netherlands: Springer, 2006.

[19] Z. Zong and Y. Zhang, Advanced Differential Quadrature Methods. 1st ed. USA: CRC Press, 2009.

[20] H. Zhong and T. Yu, "A weak form quadrature element method for plane elasticity problems," Appl. Math. Modell., vol. 33, pp. 3801-3814, 2009.

[21] S. Maleki and M. Tahani, "Non-linear analysis of fiber-reinforced open conical shell panels considering variation of thickness and fiber orientation under thermo-mechanical loadings," Compos. B Eng., vol. 52, pp. 245-261, 2013.

[22] A. Alibeigloo and M. Shakeri, "Elasticity solution for static analysis of laminated cylindrical panel using differential quadrature method," Eng. Struct., vol. 31, pp. 260267, 2009.

[23] F. Tornabene, N. Fantuzzi, E. Viola, and E. Carrera, "Static analysis of doublycurved anisotropic shells and panels using CUF approach, differential geometry and differential quadrature method," Compos. Struct., vol. 107, pp. 675-697, 2014.

[24] P. Malekzadeh, "Differential quadrature large amplitude free vibration analysis of laminated skew plates based on FSDT," Compos. Struct., vol. 83, pp. 189-200, 2008. 
[25] E. Viola, F. Tornabene, and N. Fantuzzi, "Generalized differential quadrature finite element method for cracked composite structures of arbitrary shape," Compos. Struct., vol. 106, pp. 815-834, 2013.

[26] A.J.M. Ferreira et al., "Analysis of thick isotropic and cross-ply laminated plates by generalized differential quadrature method and a unified formulation," Compos. B Eng., vol. 58, pp. 544-552, 2014.

[27] Ö. Civalek, "Nonlinear analysis of thin rectangular plates on Winkler-Pasternak elastic foundations by DSC-HDQ methods," Appl. Math. Modell., vol. 31, pp. 606-624, 2007.

[28] S. Maleki, M. Tahani, and A. Andakhshideh, "Transient response of laminated plates with arbitrary laminations and boundary conditions under general dynamic loadings," Arch. Appl. Mech., vol. 82, pp. 615-630, 2011.

[29] C.C. Hong, "Transient responses of magnetostrictive plates by using the GDQ method," Eur. J. Mech. A Solids, vol. 29, pp. 1015-1021, 2010.

[30] J.S. Peng, Y.Q. Yuan, J. Yang, and S. Kitipornchai, “A semi-analytic approach for the nonlinear dynamic response of circular plates," Appl. Math. Modell., vol. 33, pp. 4303-4313, 2009.

[31] Ö. Civalek, "Geometrically nonlinear dynamic analysis of doubly curved isotropic shells resting on elastic foundation by a combination of harmonic differential quadraturefinite difference methods," Int. J. Press. Vessels Pip., vol. 82, pp. 470-479, 2005.

[32] Z. Kazanc1, "A review on the response of blast loaded laminated composite plates," Prog. Aerosp. Sci., vol. 81, pp. 49-59, 2016. 
[33] Z. Kazanc1 and Z. Mecitoğlu, "Nonlinear damped vibrations of a laminated composite plate subjected to blast load," AIAA J., vol. 44, pp. 2002-2008, 2006.

[34] Z. Kazancı and Z. Mecitoğlu, "Nonlinear dynamic behavior of simply supported laminated composite plates subjected to blast load," J. Sound Vib., vol. 317, pp. 883-897, 2008 .

[35] A.K. Upadhyay, R. Pandey, and K.K. Shukla, "Nonlinear dynamic response of laminated composite plates subjected to pulse loading," Commun. Nonlinear Sci. Numer. Simul., vol. 16, pp. 4530-4544, 2011.

[36] Z. Kazanc1, "Computational methods to predict the nonlinear dynamic response of blast loaded laminated composite plates," in Explosion Blast Response of Composites, 1st ed., A.P. Mouritz and Y.D.S. Rajapakse, Eds. UK: Woodhead Publishing Elsevier, 2017, pp. 85-112.

[37] H.S. Türkmen and Z. Mecitoğlu, "Dynamic response of a stiffened laminated composite plate subjected to blast load," J. Sound Vib., vol. 221, pp. 371-389, 1999.

[38] S. Susler, H.S. Turkmen, and Z. Kazanc1, "The nonlinear dynamic behaviour of tapered laminated plates subjected to blast loading," Shock Vib., vol. 19, pp. 1235-1255, 2012

[39] N.D. Duc, N.D. Tuan, P. Tran, and T.Q. Quan, "Nonlinear dynamic response and vibration of imperfect shear deformable functionally graded plates subjected to blast and thermal loads," Mech. Adv. Mater. Struct., vol 24, pp. 318-329, 2017.

[40] A. Rajamani and R. Prabhakaran, "Response of composite plates to blast loading," Exp. Mech., vol. 20, pp. 245-250, 1980. 
[41] D. Balkan and Z. Mecitoğlu, "Nonlinear dynamic behavior of viscoelastic sandwich composite plates under non-uniform blast load: Theory and experiment," Int. J. Impact Eng., vol. 72, pp. 85-104, 2014.

[42] S.A. Tekalur, A. Shukla, and K. Shivakumar, "Blast resistance of polyurea based layered composite materials," Compos. Struct., vol. 84, pp. 271-281, 2008.

[43] C. Shillings et al., "Experimental and computational investigation of the blast response of carbon-epoxy weathered composite materials," Compos. B Eng., vol. 129, pp. 107-116, 2017.

[44] “ASTM D638-14 Standard Test Methods for Tensile Properties of Plastics,” ASTM International, 2014. https://doi.org/10.1520/D0638-14

[45] “ASTM D3518M-13 Standard Test Methods for In-Plane Shear Response of Polymer Matrix Composite Materials by Tensile Test of a $\pm 45^{\circ}$ Laminate," ASTM International, 2013. https://doi.org/ 10.1520/D3518_D3518M

[46] Performance Composites Ltd. "Mechanical properties of carbon fibre composite materials," [Online]. Available: http://www.performancecomposites.com/carbonfibre/mechanicalproperties_2.asp. Accessed: Mar. 10, 2018.

\section{Figure Captions}

Figure 1. The schematic view of the laminated basalt composite plate.

Figure 2. Grid points for discretization.

Figure 3. The views from the curing process of manufacturing.

Figure 4. The schematic overview for blast tests. 
Figure 5. General views from experimental studies on plates subjected to the blast load.

Figure 6. Points for pressure sensors on the plate.

Figure 7. The magnitudes for peak pressure at the center of the plate.

Figure 8. Sensitivity analysis of GDQ method.

Figure 9. Sensitivity analysis of ANSYS.

Figure 10. Displacement-time histories at certain points of plate 1.

Figure 11. Displacement-time histories at certain points of plate 2.

Figure 12. Displacement-time histories at certain points of plate 3 .

Figure 13. Displacement-time histories at certain points of plate 4.

Figure 14. Strain-time histories at point $(a / 2 ; b / 2)$ on the top surface of plate 1 .

Figure 15. Strain-time histories at point $(a / 4 ; b / 4)$ on the top surface of plate 1 .

Figure 16. Strain-time histories at point $(a / 2 ; b / 2)$ on the top surface of plate 2 .

Figure 17. Strain-time histories at point $(a / 4 ; b / 4)$ on the top surface of plate 2 .

Figure 18. Strain-time histories at point $(a / 2 ; b / 2)$ on the top surface of plate 3 .

Figure 19. Strain-time histories at point $(a / 4 ; b / 4)$ on the top surface of plate 3 .

Figure 20. Strain-time histories at point $(a / 2 ; b / 2)$ on the top surface of plate 4 .

Figure 21. Strain-time histories at point $(a / 4 ; b / 4)$ on the top surface of plate 4 .

Figure 22. Acceleration-time histories at point $(a / 2 ; b / 2)$ for plate 1.

Figure 23. Acceleration-time histories at point $(a / 4 ; b / 4)$ for plate 1 .

Figure 24. Displacement-time histories at point $(a / 2 ; b / 2)$ of plate 1 for different types of fibers.

Figure 25. Strain-time histories at point $(a / 2 ; b / 2)$ of plate 1 for different types of fibers. 
Figure 26. Acceleration-time histories at point $(a / 2 ; b / 2)$ of plate 1 for different types of fibers.

Table 1. Material properties of the basalt fabric-epoxy with bidirectional $\left(0^{\circ} / 90^{\circ}\right)$ fiber orientation.

\begin{tabular}{cccccc}
\hline Material Property & Test 1 & Test 2 & Test 3 & Test 4 & Average \\
\hline$E_{1}=E_{2}(\mathrm{GPa})$ & 22.72 & 24.93 & 23.61 & 22.73 & 23.5 \\
$v_{12}$ & 0.08 & 0.13 & 0.10 & 0.11 & 0.11 \\
$G_{12}(\mathrm{GPa})$ & 9.18 & 9.13 & 9.32 & 8.51 & 9.04 \\
$\rho\left(\mathrm{kg} / \mathrm{m}^{3}\right)$ & & & & & 2320 \\
\hline
\end{tabular}

Table 2. The design configurations for the laminated basalt composite plate.

\begin{tabular}{rcc}
\hline Plate No & Lay-up & Total Thickness $(\mathrm{mm})$ \\
\hline 1 & {$[0 / 0 / 0 / 0 / 0 / 0 / 0 / 0]_{\mathrm{S}}$} & 2.50 \\
2 & {$[0 / 0 / 0 / 0]_{\mathrm{S}}$} & 1.40 \\
3 & {$[0 / 45 / 0 / 45 / 0 / 45 / 0 / 45]_{\mathrm{S}}$} & 2.90 \\
4 & {$[0 / 45 / 0 / 45]_{\mathrm{S}}$} & 1.58 \\
\hline
\end{tabular}

Table 3. Measured results of pressure distribution for Friedlander's waveform.

\begin{tabular}{ccccc}
\hline Test & Point ID & $P_{m}(\mathrm{kPa})$ & $t_{p}(\mathrm{~ms})$ & $\varphi$ \\
\hline \multirow{3}{*}{1} & P1 & 31.19 & 0.93 & 0.54 \\
& P2 & 29.18 & 0.73 & 0.64 \\
& P3 & 29.51 & 0.87 & 0.50 \\
\hline \multirow{3}{*}{2} & P1 & 27.75 & 0.71 & 0.66 \\
& P4 & 28.08 & 0.93 & 0.28 \\
& P5 & 26.75 & 0.90 & 0.42 \\
\hline \multirow{3}{*}{3} & P1 & 28.10 & 0.70 & 0.89 \\
& P6 & 29.46 & 0.90 & 0.57 \\
& P7 & 29.63 & 0.68 & 1.27 \\
\hline \multirow{3}{*}{4} & P1 & 26.85 & 0.98 & 0.33 \\
& P8 & 28.72 & 1.02 & 0.10 \\
& P9 & 28.44 & 0.99 & 0.10 \\
\hline \multirow{2}{*}{5} & P1 & 27.69 & 1.06 & 0.38 \\
& P10 & 27.18 & 1.06 & 0.30 \\
& P11 & 26.96 & 0.95 & 1.02 \\
\hline
\end{tabular}




\begin{tabular}{ccccc}
\hline \multirow{6}{*}{6} & P1 & 26.98 & 0.70 & 0.95 \\
& P12 & 28.12 & 1.01 & 0.42 \\
& P13 & 27.31 & 0.97 & 0.10 \\
\hline \multirow{3}{*}{7} & P1 & 28.92 & 0.70 & 0.97 \\
& P14 & 30.95 & 1.06 & 0.25 \\
& P15 & 28.46 & 0.69 & 0.66 \\
\hline \multirow{3}{*}{8} & P1 & 27.46 & 0.96 & 0.84 \\
& P16 & 29.27 & 0.98 & 0.30 \\
& P17 & 29.80 & 0.95 & 0.32 \\
\hline
\end{tabular}

Table 4. Error results of time histories and first peak values.

\begin{tabular}{|c|c|c|c|c|c|c|c|c|}
\hline \multirow{2}{*}{$\operatorname{MAPE}(\%)$} & \multicolumn{4}{|c|}{$(\mathrm{a} / 2 ; \mathrm{b} / 2)$} & \multicolumn{4}{|c|}{$(\mathrm{a} / 4 ; \mathrm{b} / 4)$} \\
\hline & \multicolumn{2}{|c|}{ Displ.-Time } & \multicolumn{2}{|c|}{$\varepsilon_{x}^{\text {top }}$-Time } & \multicolumn{2}{|c|}{ Displ.-Time } & \multicolumn{2}{|c|}{$\varepsilon_{x}{ }^{\text {top-Time }}$} \\
\hline Plate 1 & \multicolumn{2}{|c|}{1.3} & \multicolumn{2}{|c|}{58.4} & \multicolumn{2}{|c|}{13.5} & \multicolumn{2}{|c|}{37743.0} \\
\hline Plate 2 & \multicolumn{2}{|c|}{4.3} & \multicolumn{2}{|c|}{51.5} & \multicolumn{2}{|c|}{17.8} & \multicolumn{2}{|c|}{47.1} \\
\hline Plate 3 & \multicolumn{2}{|c|}{8.7} & \multicolumn{2}{|c|}{513.2} & \multicolumn{2}{|c|}{18.9} & \multicolumn{2}{|c|}{18.4} \\
\hline Plate 4 & \multicolumn{2}{|c|}{10.2} & \multicolumn{2}{|c|}{34.2} & \multicolumn{2}{|c|}{11.7} & \multicolumn{2}{|c|}{24.7} \\
\hline \multirow{2}{*}{ Displ. (mm) } & \multicolumn{3}{|c|}{$(\mathrm{a} / 2 ; \mathrm{b} / 2)$} & & \multicolumn{2}{|c|}{$(a / 4 ; b / 4)$} & \multicolumn{2}{|c|}{$\%$ Error } \\
\hline & ANS & & GDQ & & & GDQ & $(\mathrm{a} / 2 ; \mathrm{b} / 2)$ & $(\mathrm{a} / 4 ; \mathrm{b} / 4)$ \\
\hline Plate 1 & 3.07 & & 3.15 & & & 0.92 & 2.8 & 8.6 \\
\hline Plate 2 & 5.50 & & 5.26 & & & 2.52 & 4.4 & 8.3 \\
\hline Plate 3 & 2.49 & & 2.58 & & & 0.67 & 3.4 & 8.5 \\
\hline Plate 4 & 5.00 & & 4.86 & & & 2.17 & 2.8 & 8.5 \\
\hline \multirow{2}{*}{$\varepsilon_{x}{ }^{t o p}$} & \multicolumn{3}{|c|}{$(\mathrm{a} / 2 ; \mathrm{b} / 2)$} & \multicolumn{3}{|c|}{$(\mathrm{a} / 4 ; \mathrm{b} / 4)$} & \multicolumn{2}{|c|}{$\%$ Error } \\
\hline & Test & GDQ & ANSYS & Test & GDQ & ANSYS & $(a / 2 ; b / 2)$ & $(\mathrm{a} / 4 ; \mathrm{b} / 4)$ \\
\hline Plate 1 & 907 & 1258 & 1283 & 321 & 443 & 412 & 38 & 38 \\
\hline Plate 2 & 1681 & 1520 & 2150 & 955 & 943 & 920 & 9.5 & 1.2 \\
\hline Plate 3 & 885 & 1135 & 1139 & 268 & 344 & 320 & 28.2 & 28.3 \\
\hline Plate 4 & 1683 & 1485 & 1780 & 859 & 863 & 803 & 11.7 & 0.4 \\
\hline
\end{tabular}

*GDQ versus average test results

Table 5. Material properties of the composite materials

\begin{tabular}{ccccc}
\hline Material Property & Basalt/Epoxy & Glass/Epoxy & Kevlar/Epoxy & Carbon/Epoxy \\
\hline$E_{l}=E_{2}(\mathrm{GPa})$ & 23.5 & 23.4 & 30 & 62.8 \\
$v_{12}$ & 0.11 & 0.115 & 0.2 & 0.06 \\
$G_{12}(\mathrm{GPa})$ & 9.04 & 5.23 & 5 & 4.37 \\
$\rho\left(\mathrm{kg} / \mathrm{m}^{3}\right)$ & 2320 & 1910 & 1400 & 1450 \\
\hline
\end{tabular}




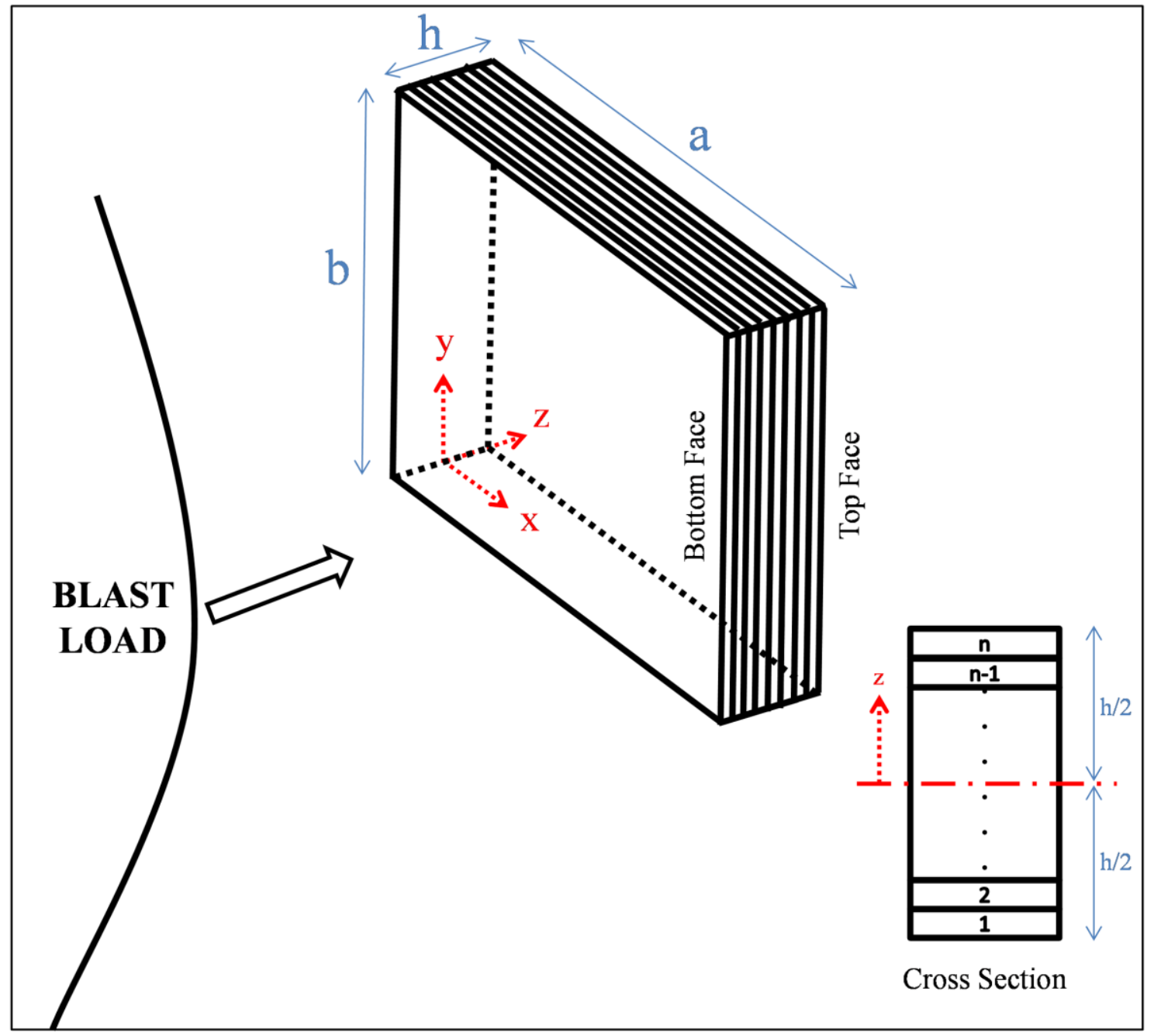

Fig 1. 


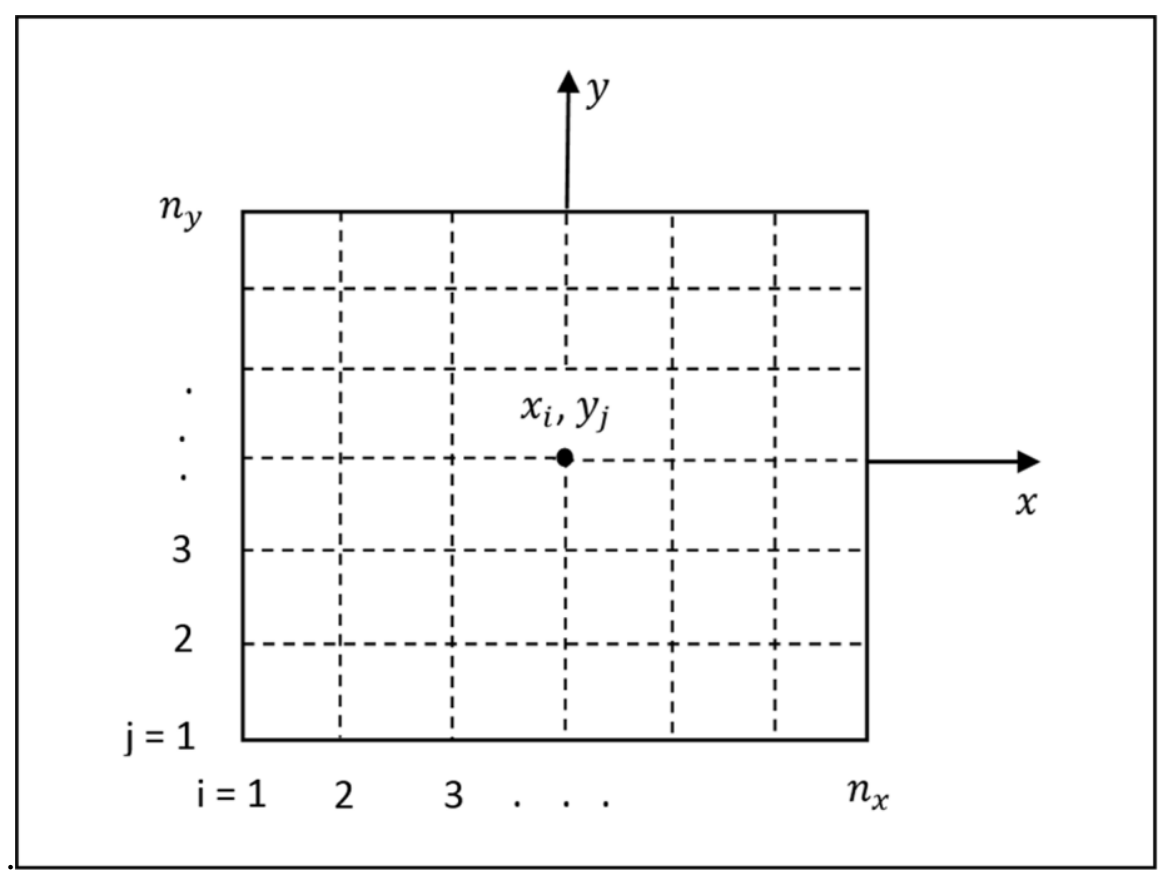

Fig 2. 


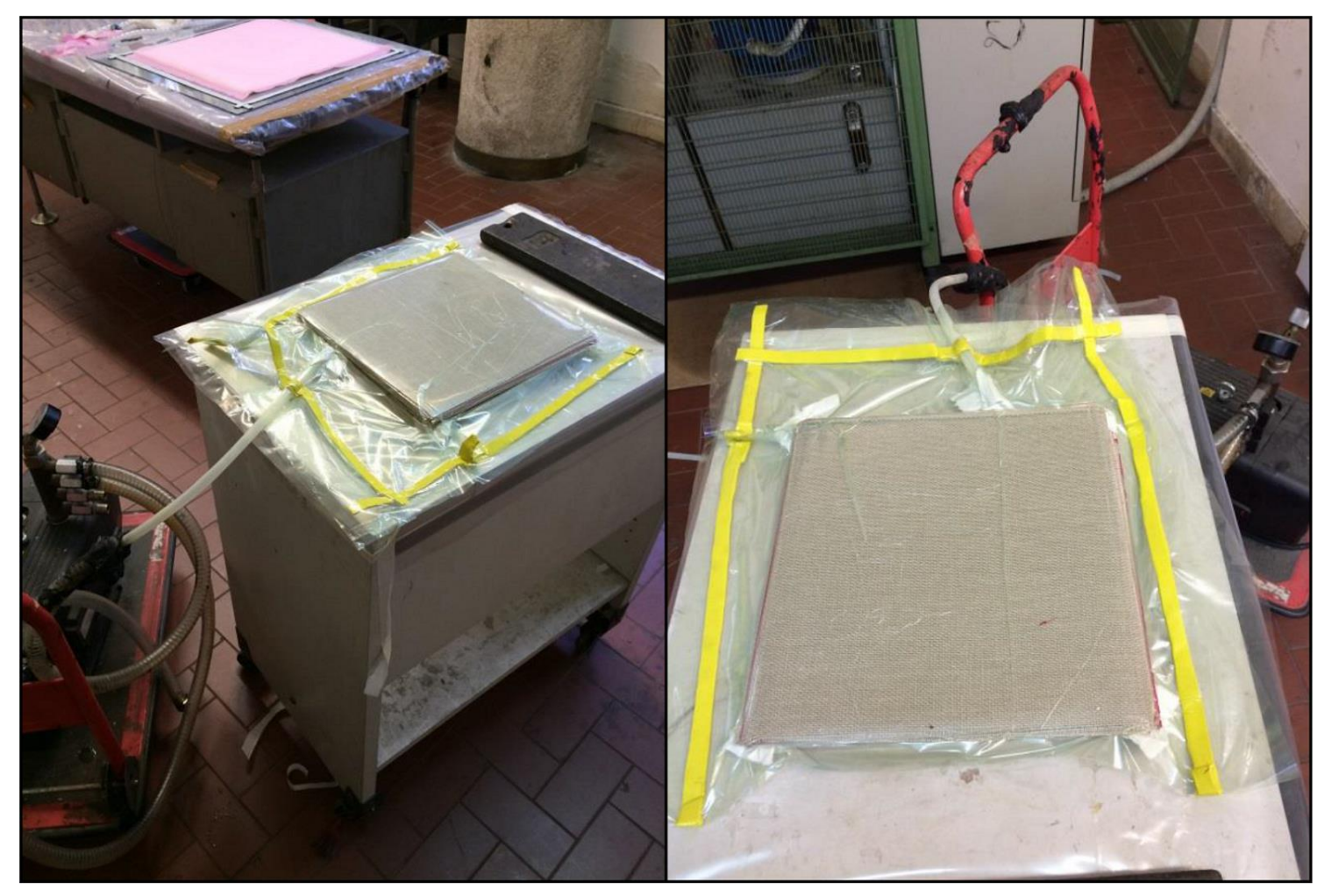

Fig 3. 


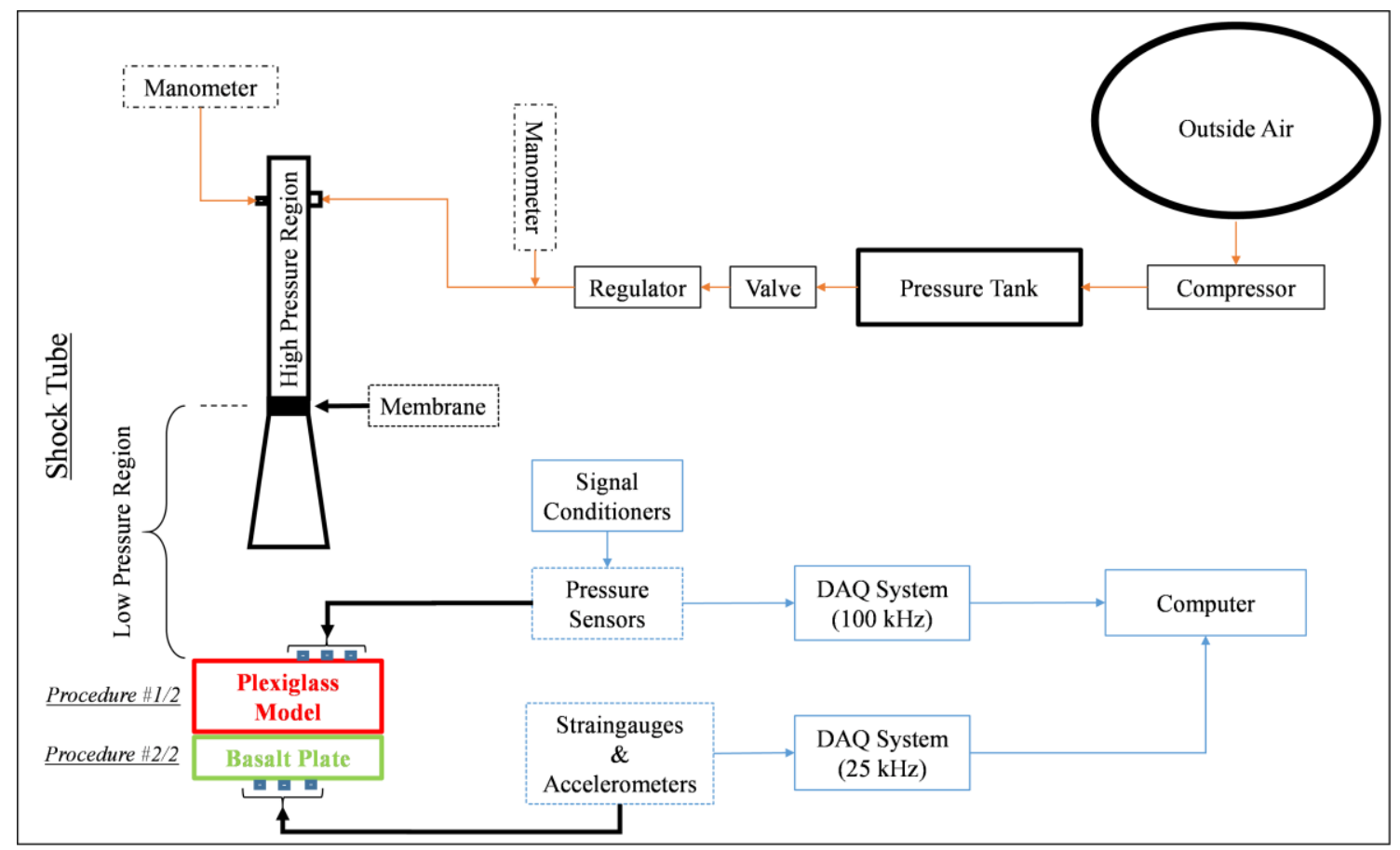

Fig 4. 


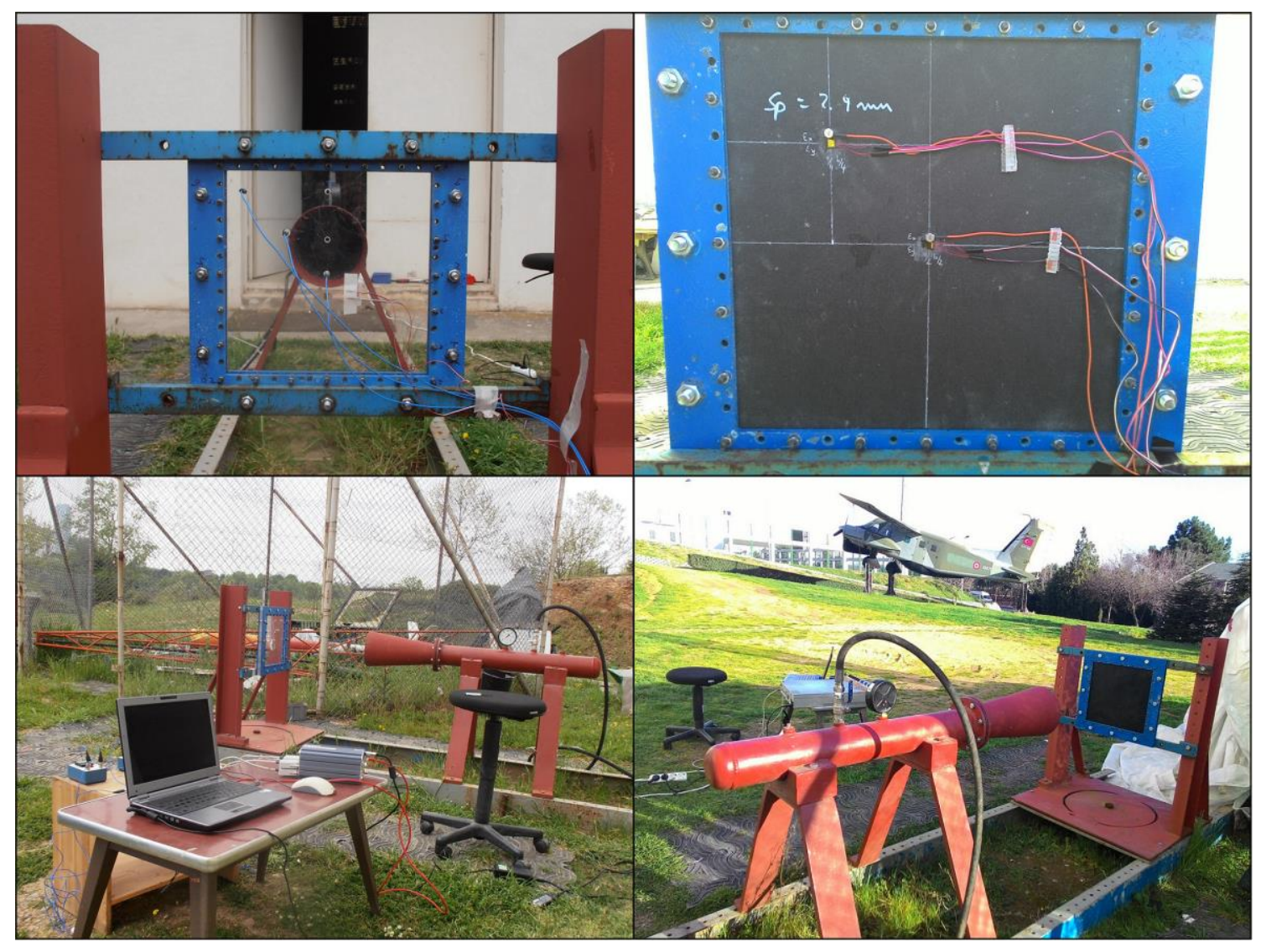

Fig 5. 


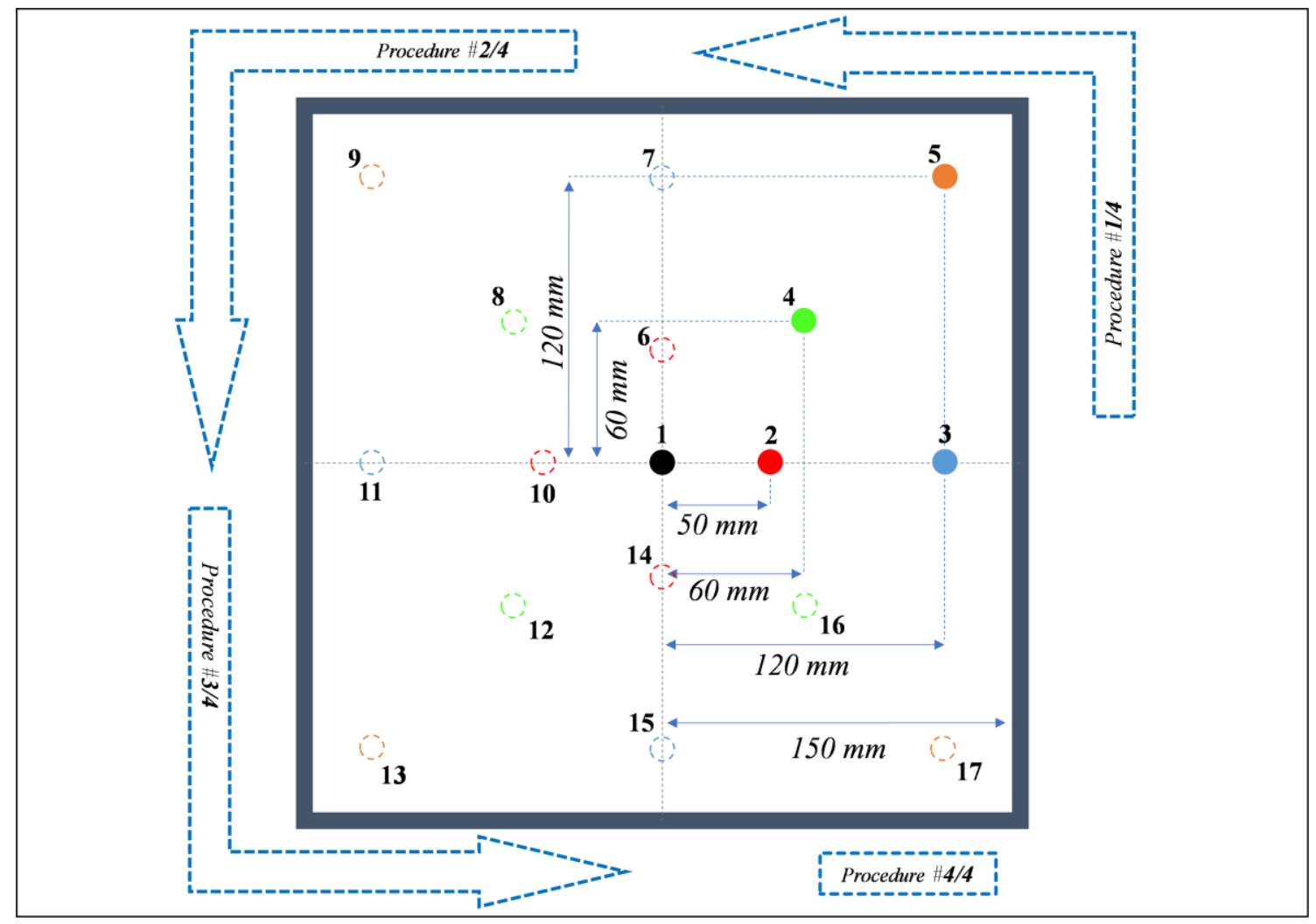

Fig 6. 


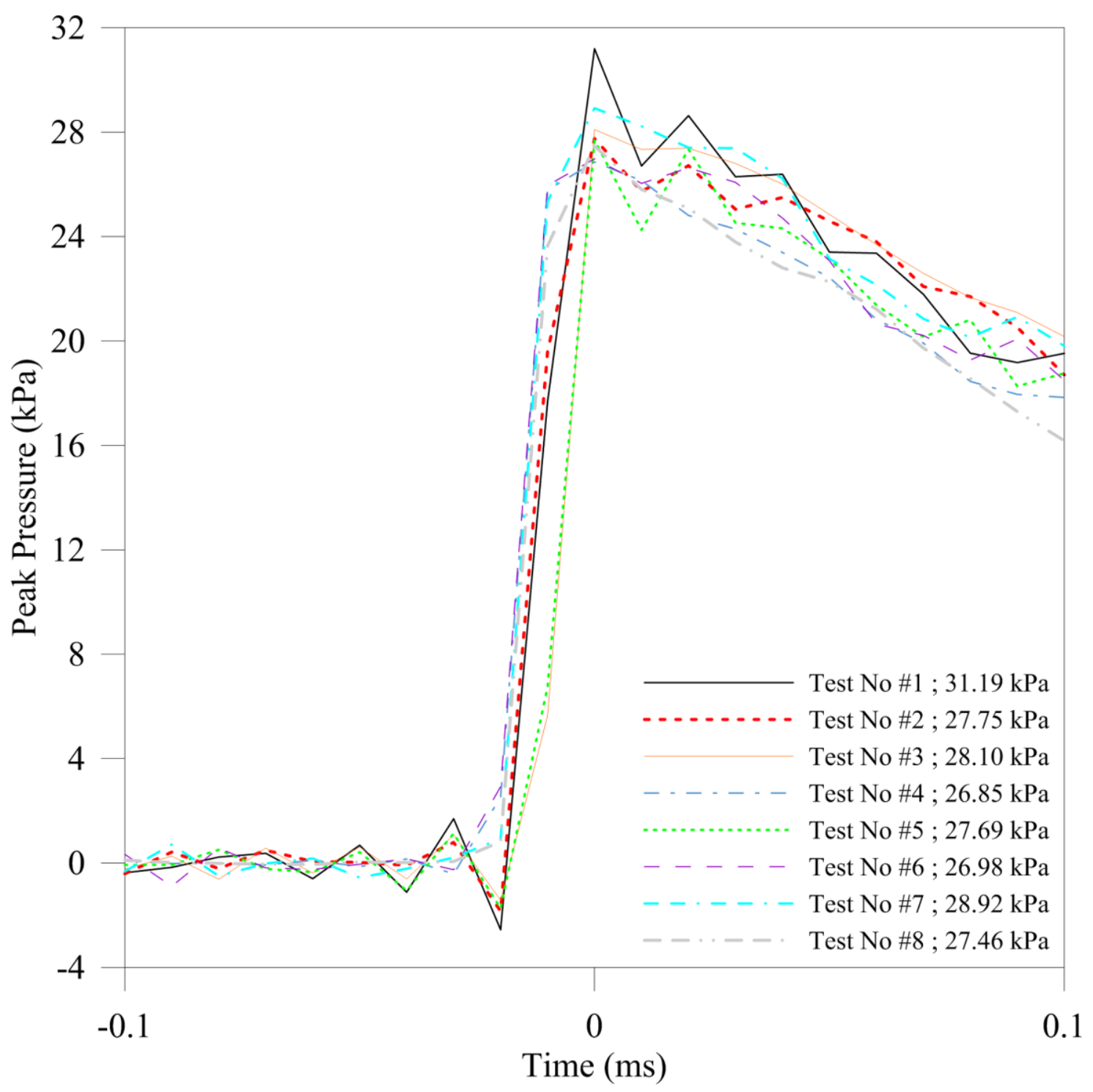

Fig 7. 


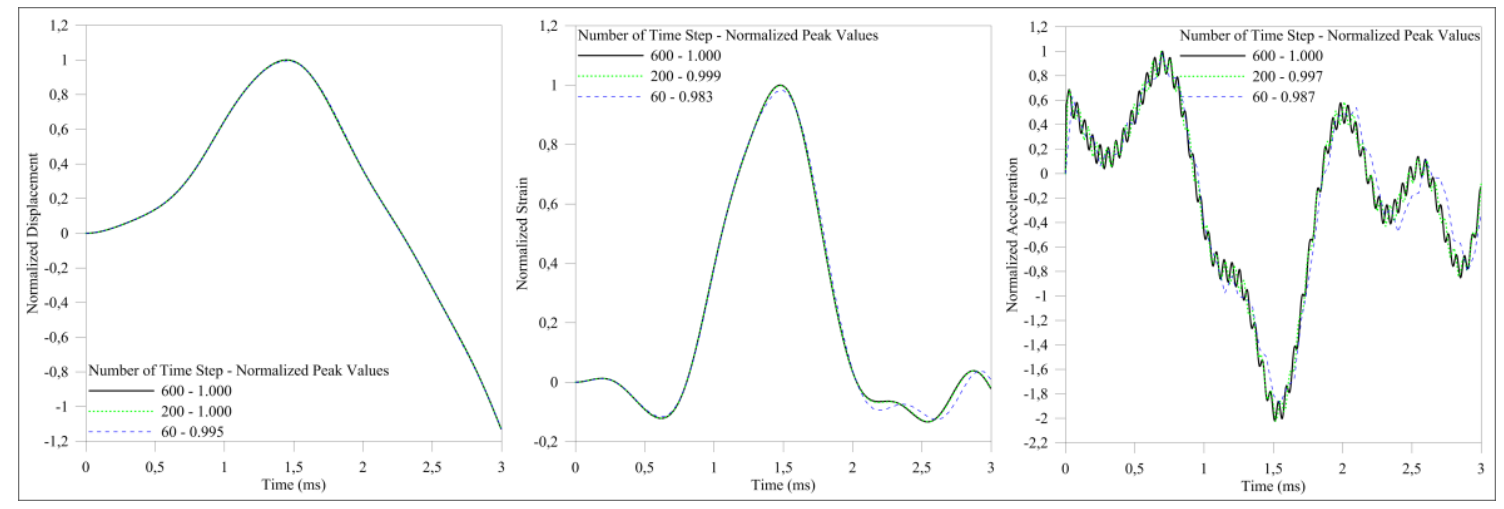

Fig 8 .

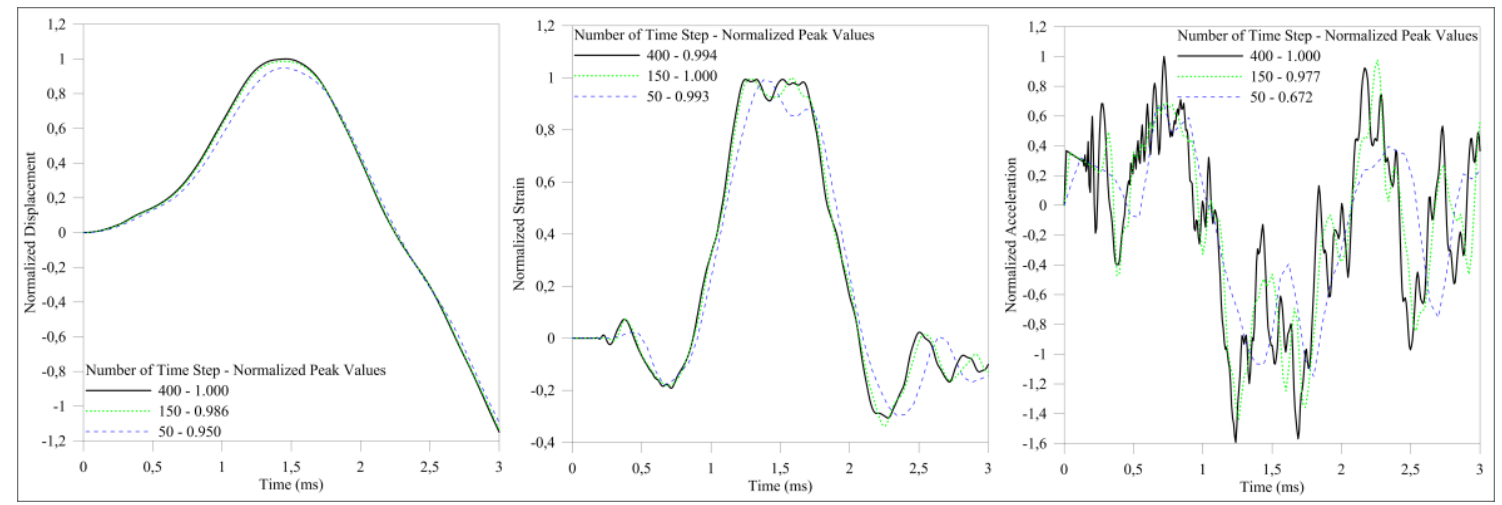

Fig 9. 


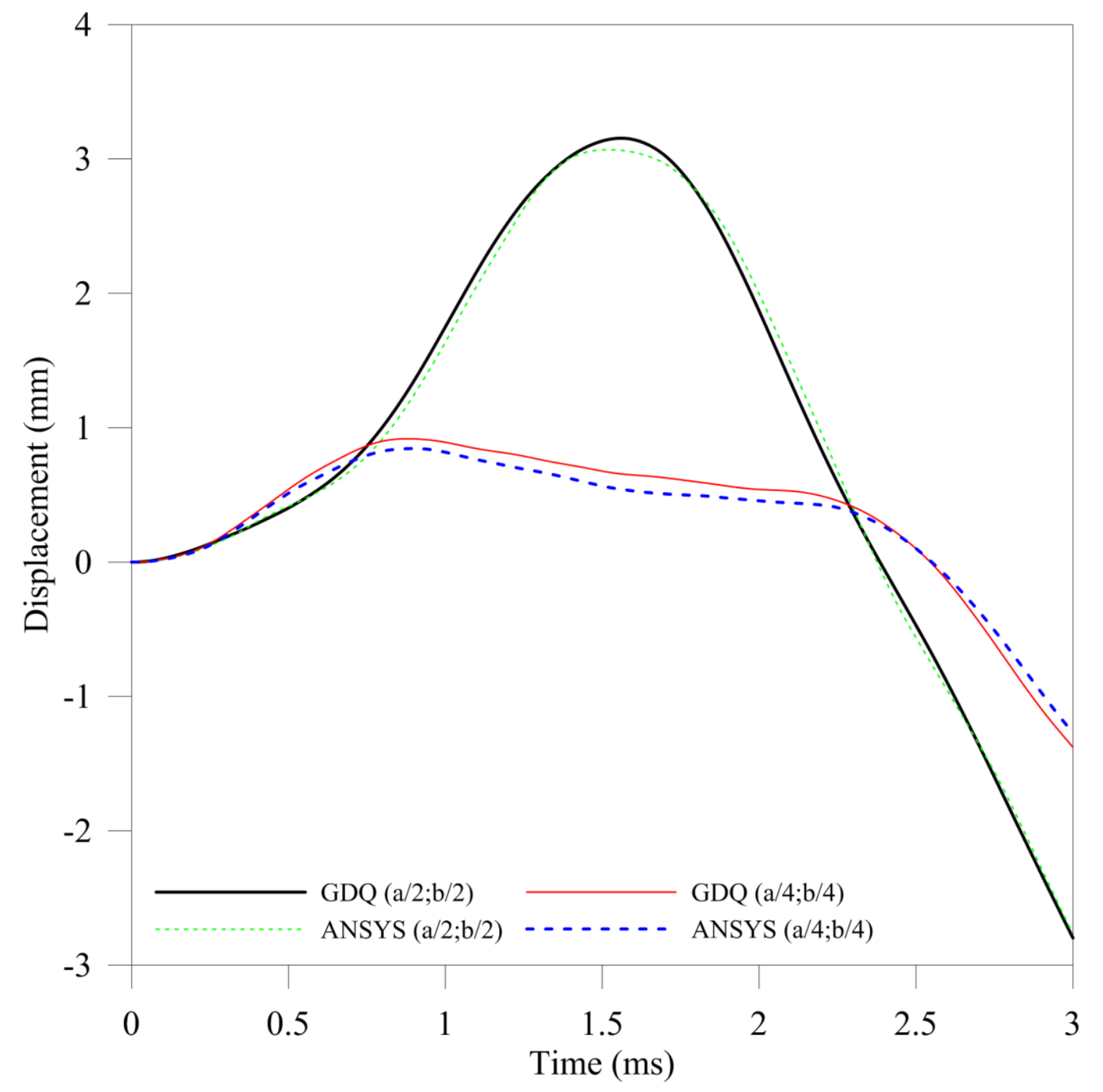

Fig 10. 


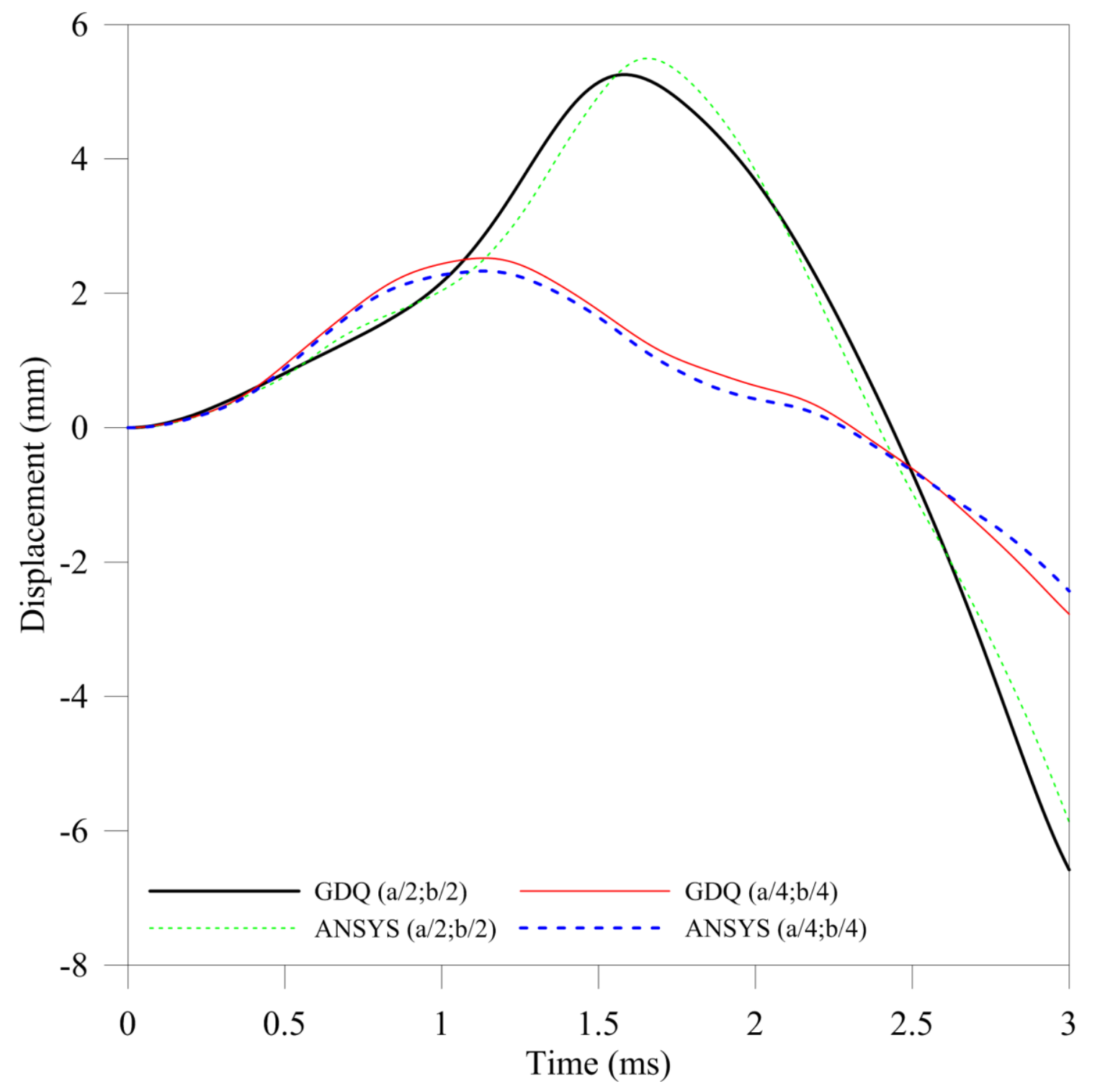

Fig 11. 


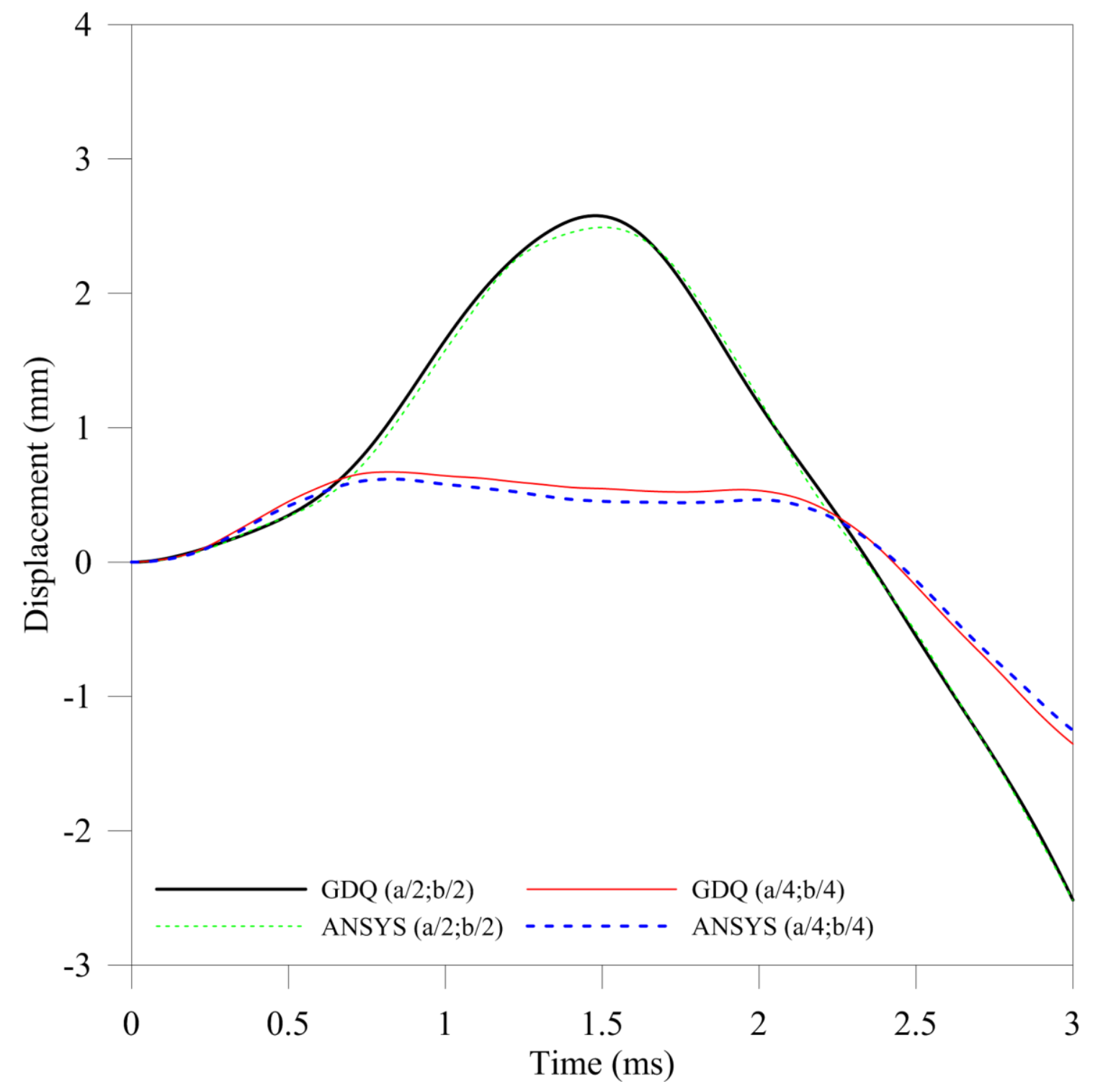

Fig 12. 


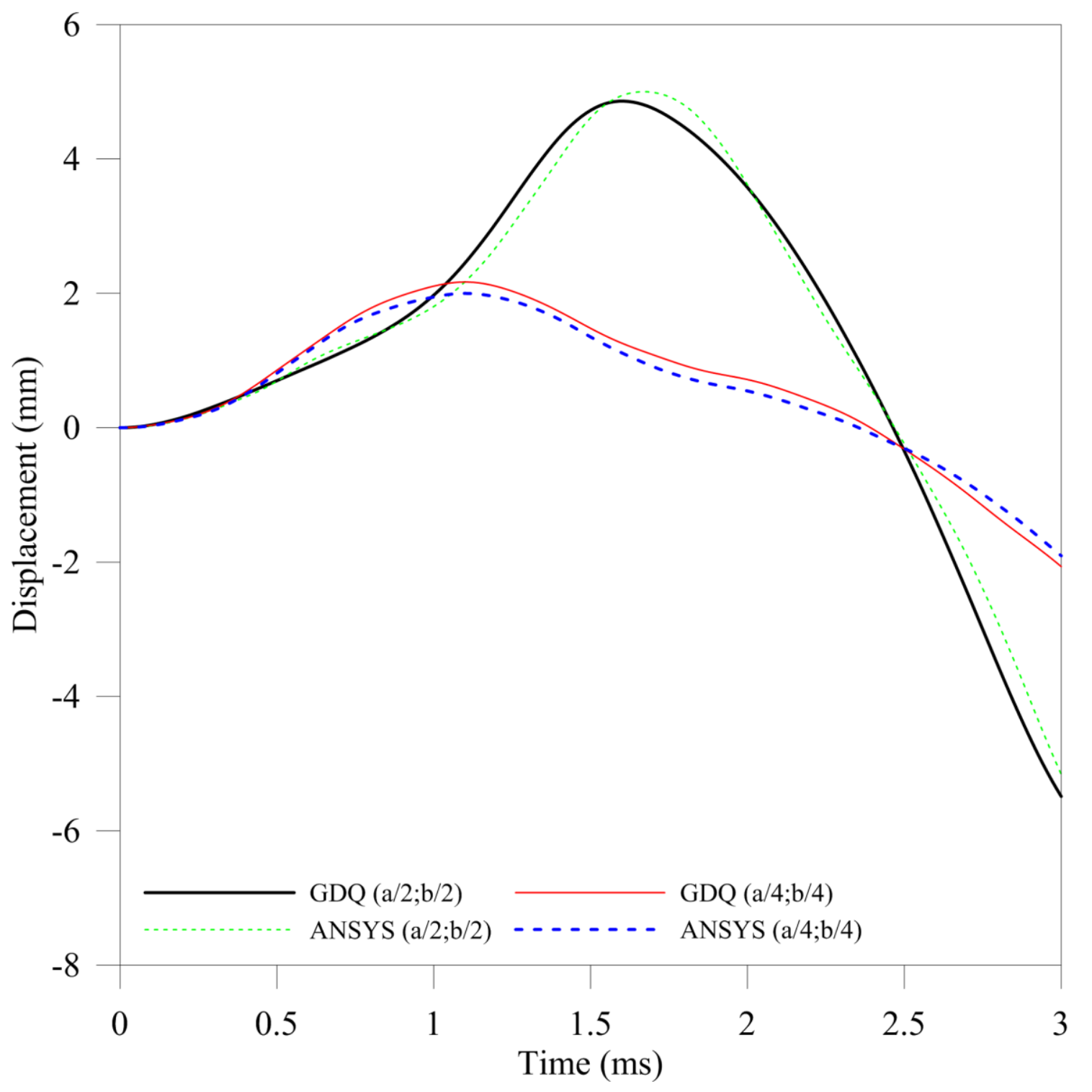

Fig 13. 


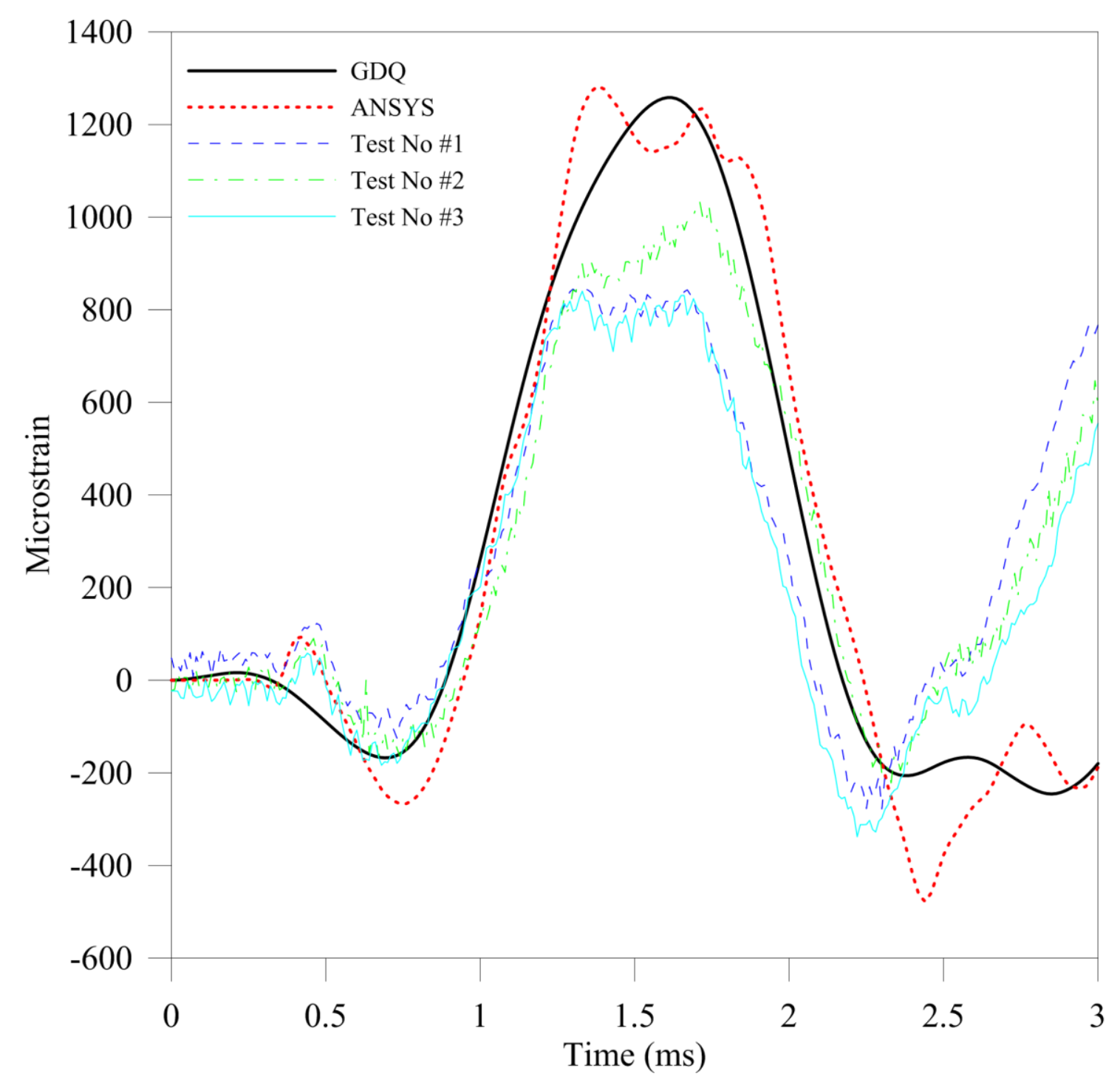

Fig 14. 


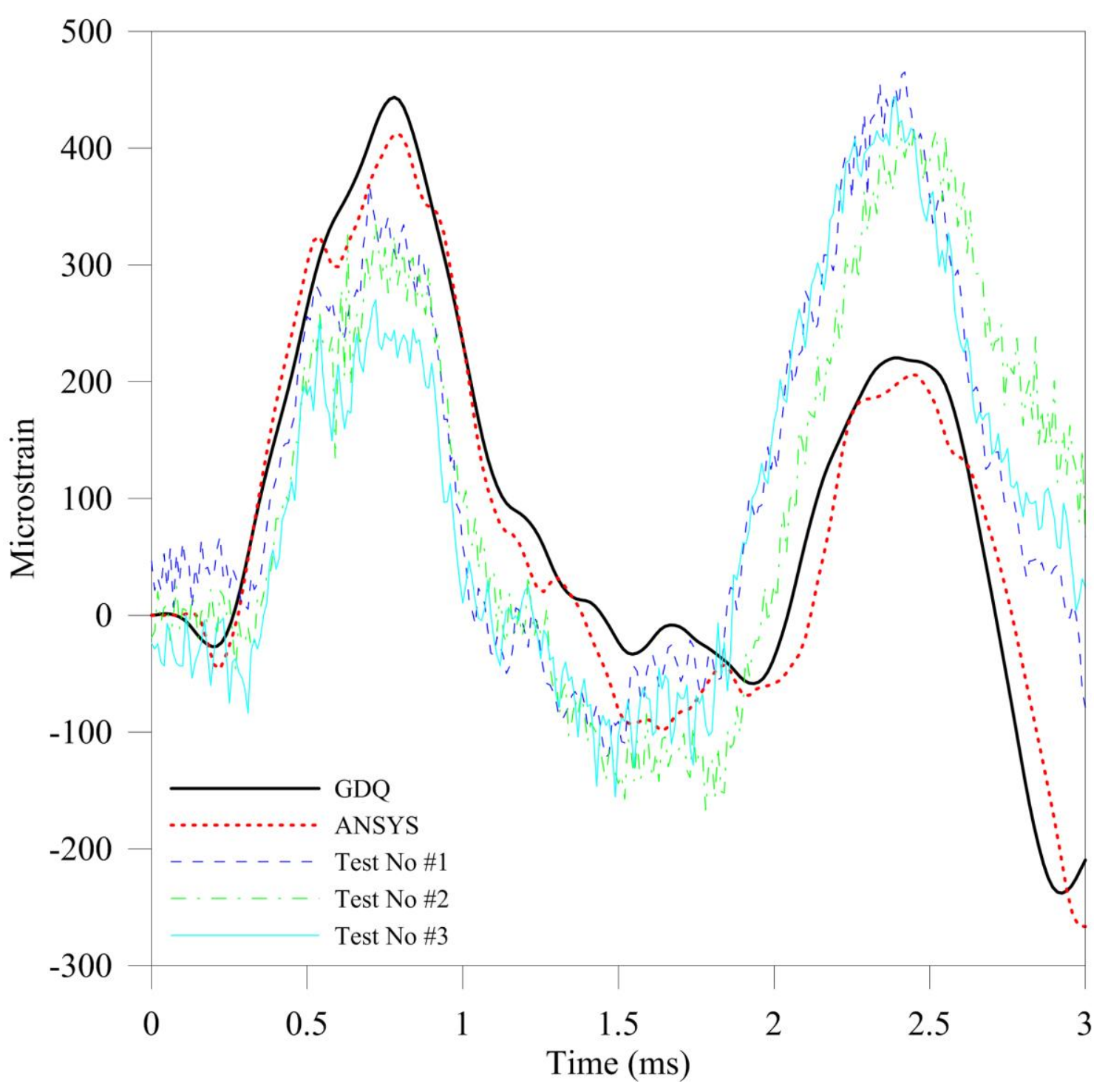

Fig 15. 


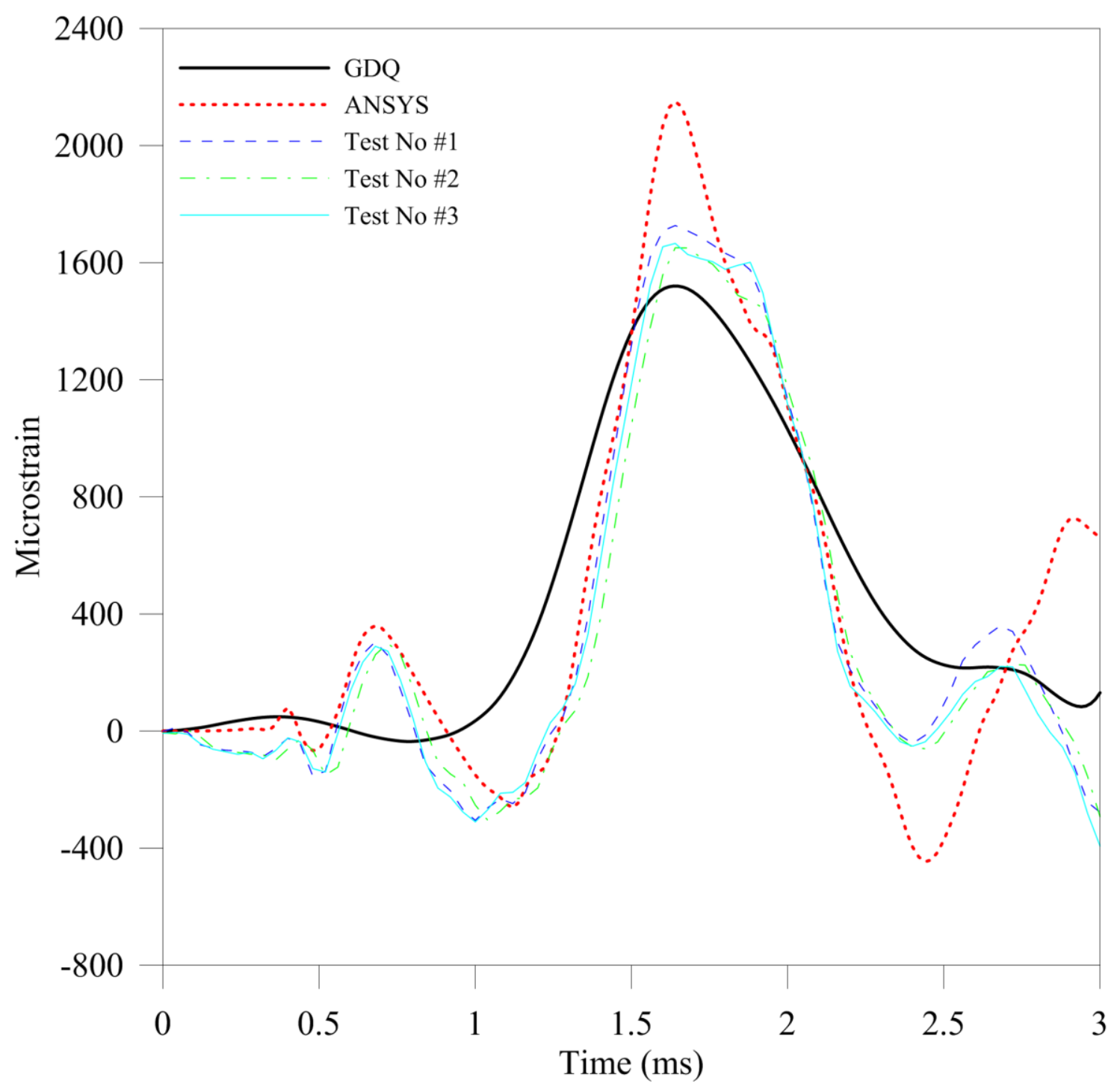

Fig 16. 


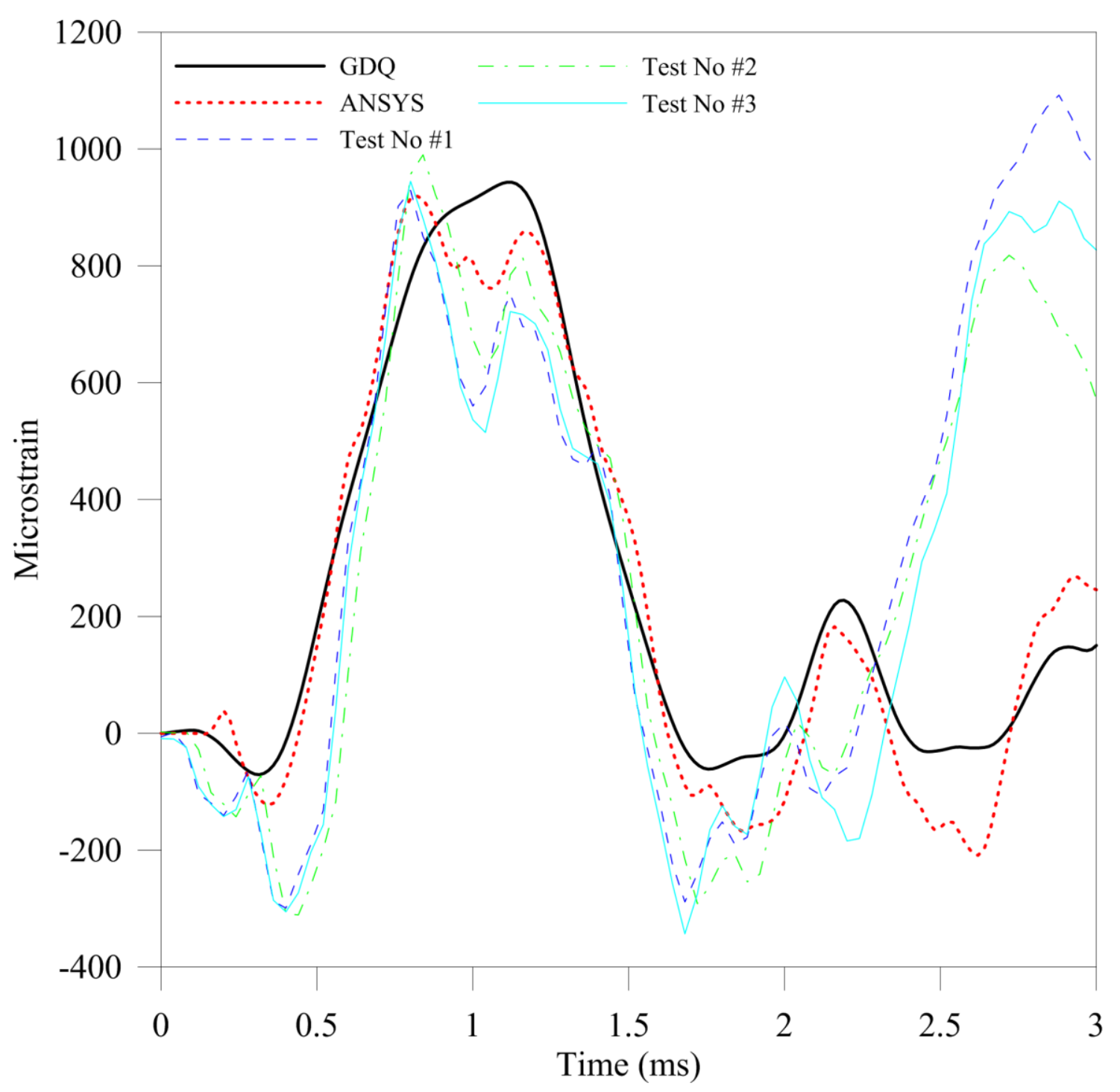

Fig 17. 


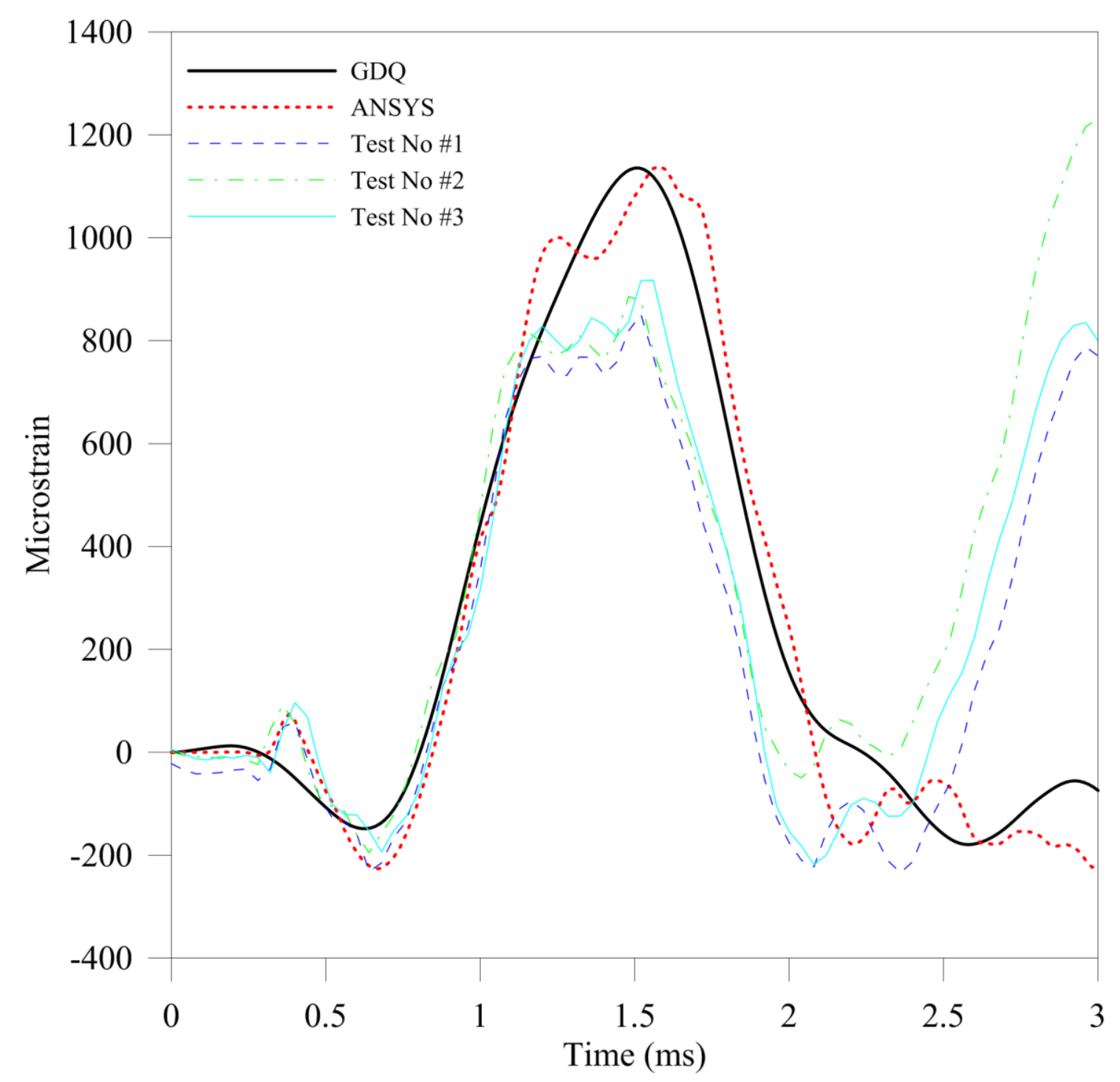

Fig 18. 


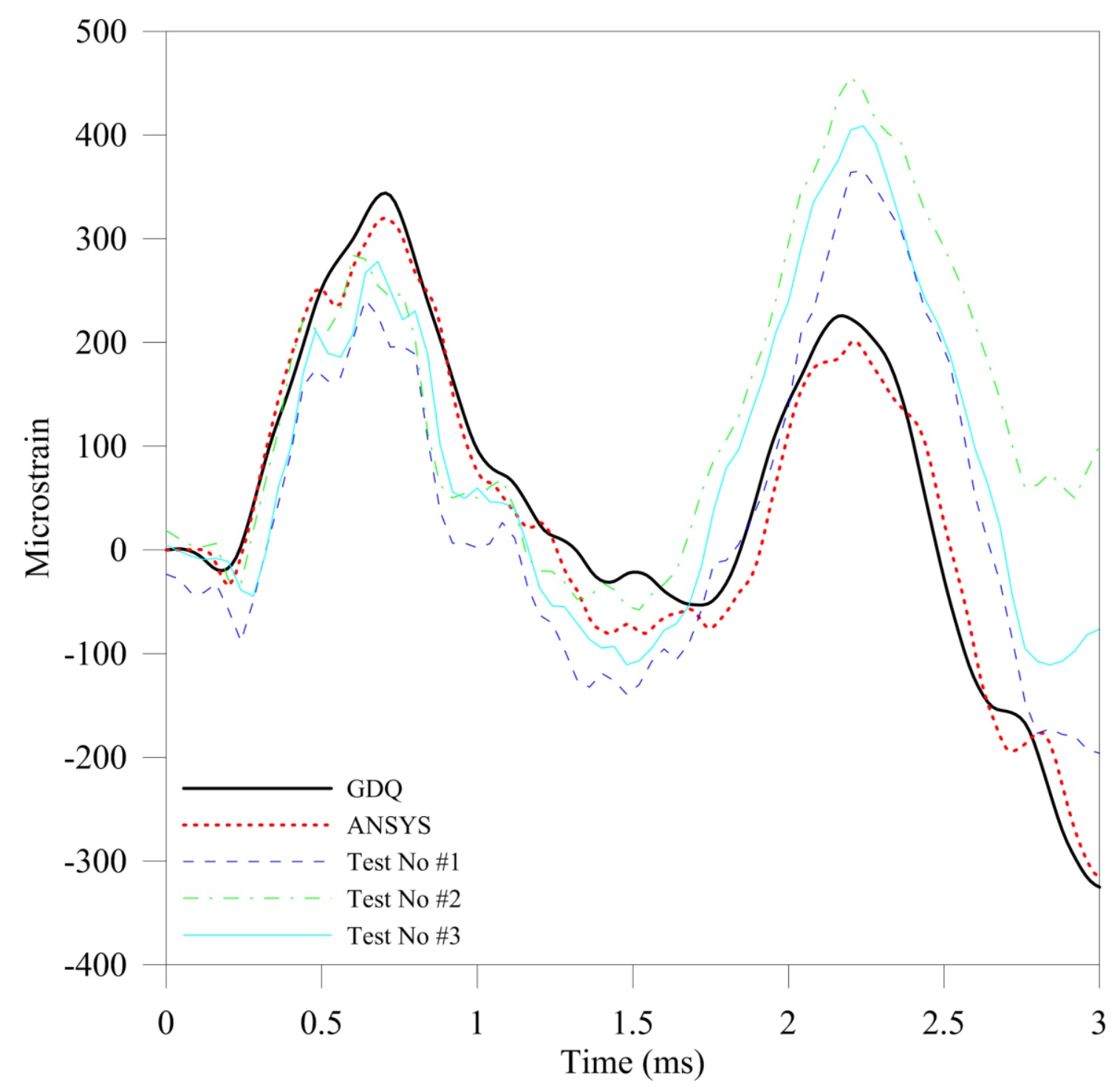

Fig 19. 


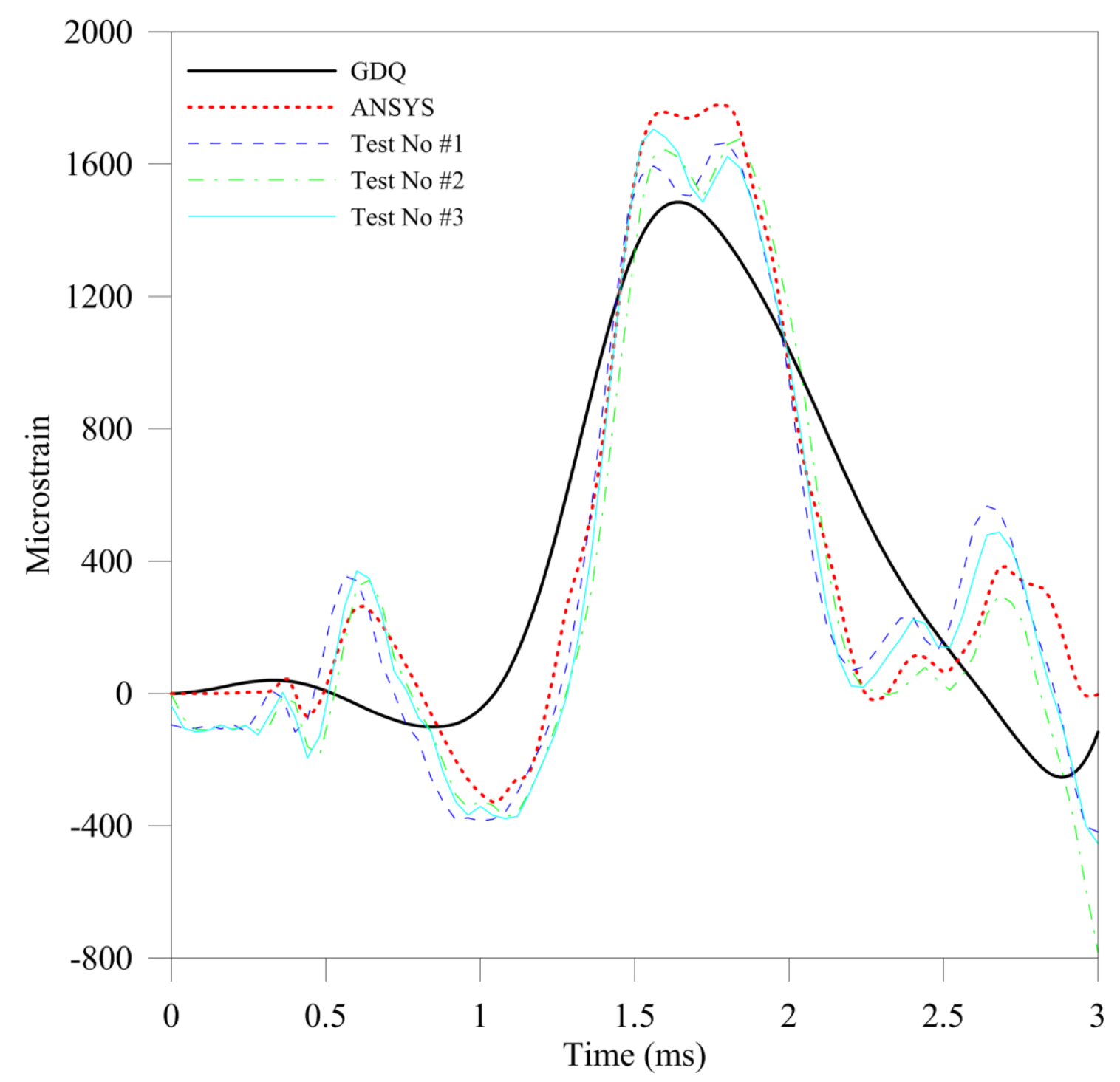

Fig 20. 


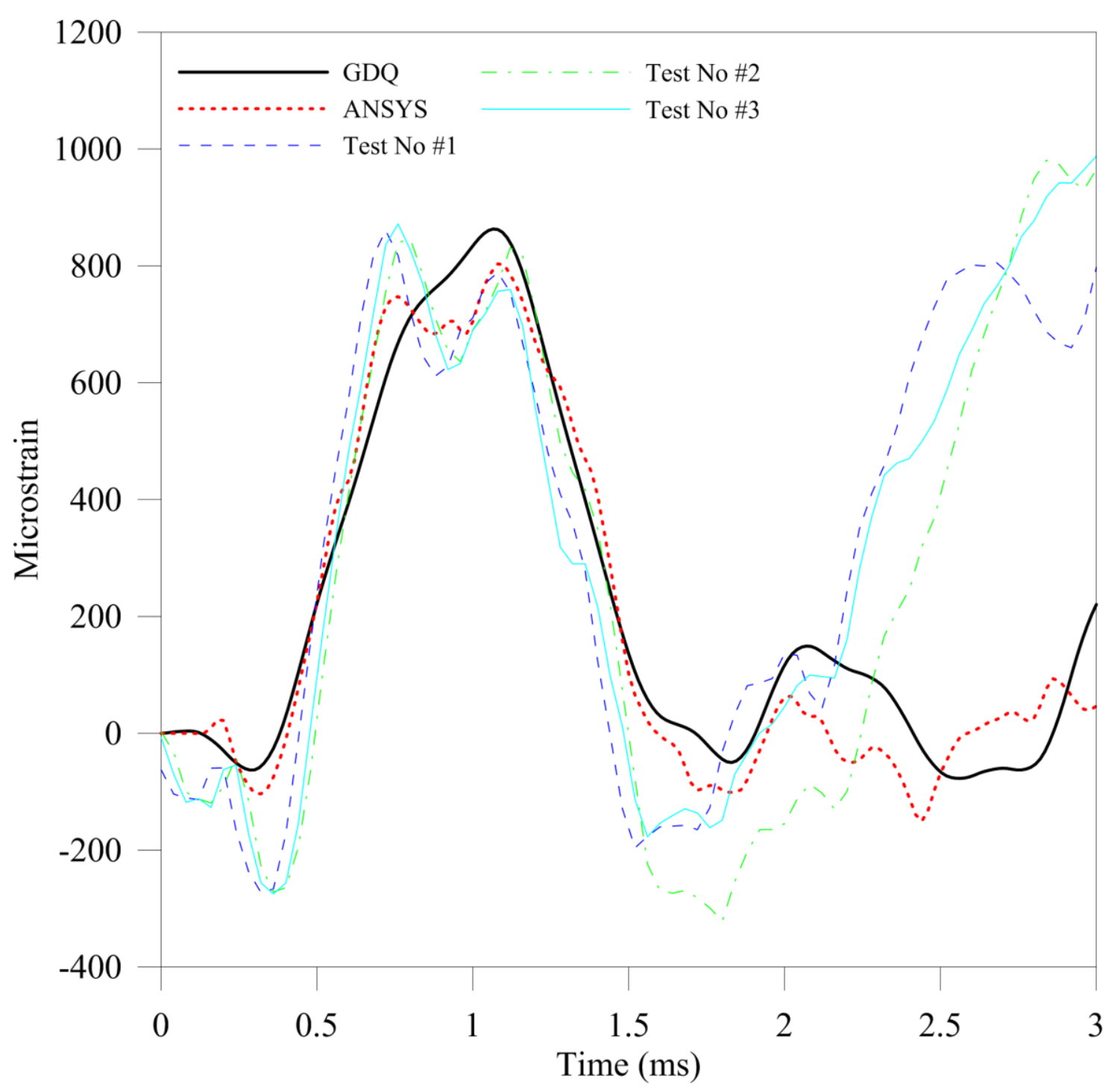

Fig 21. 


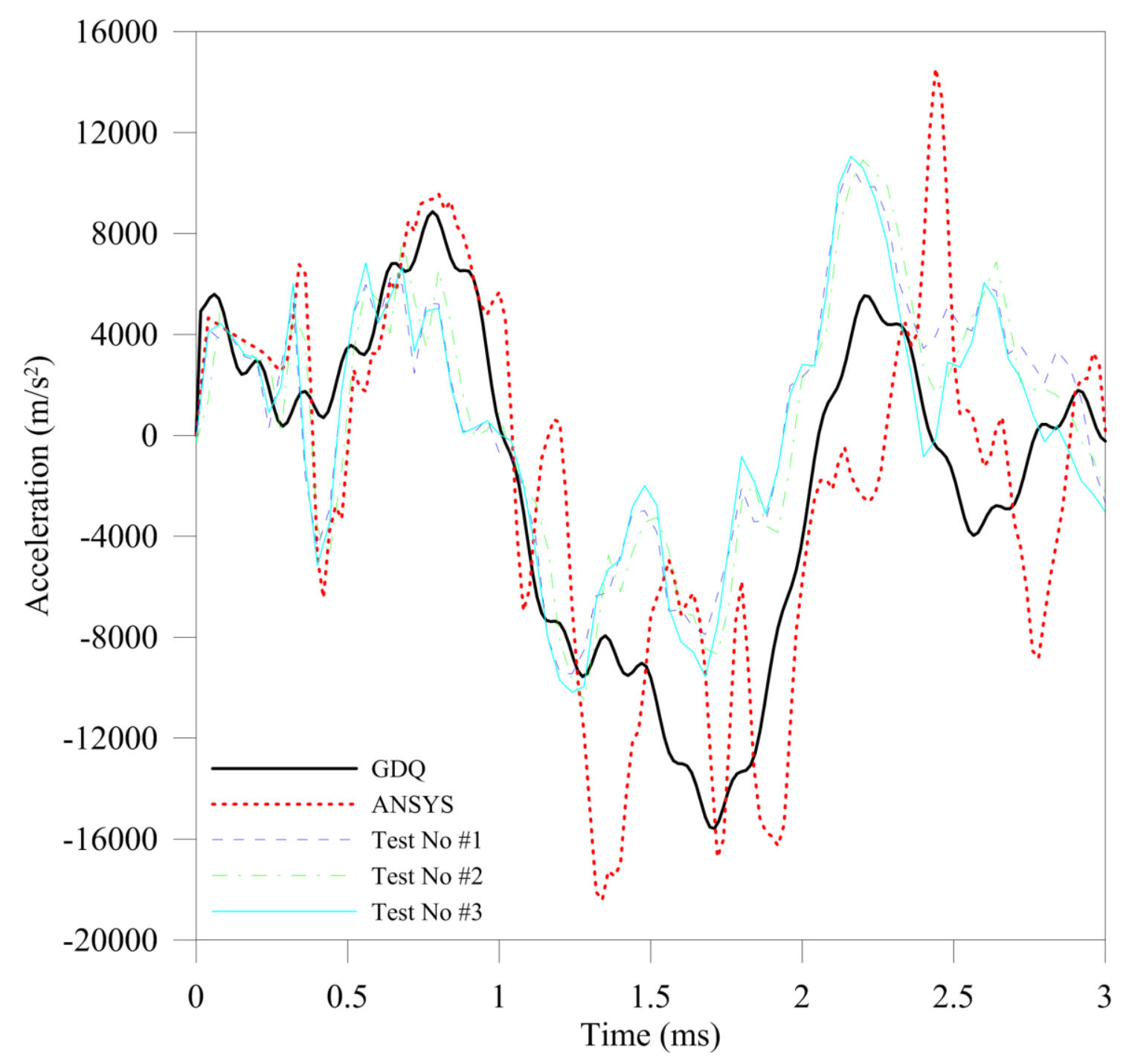

Fig 22. 


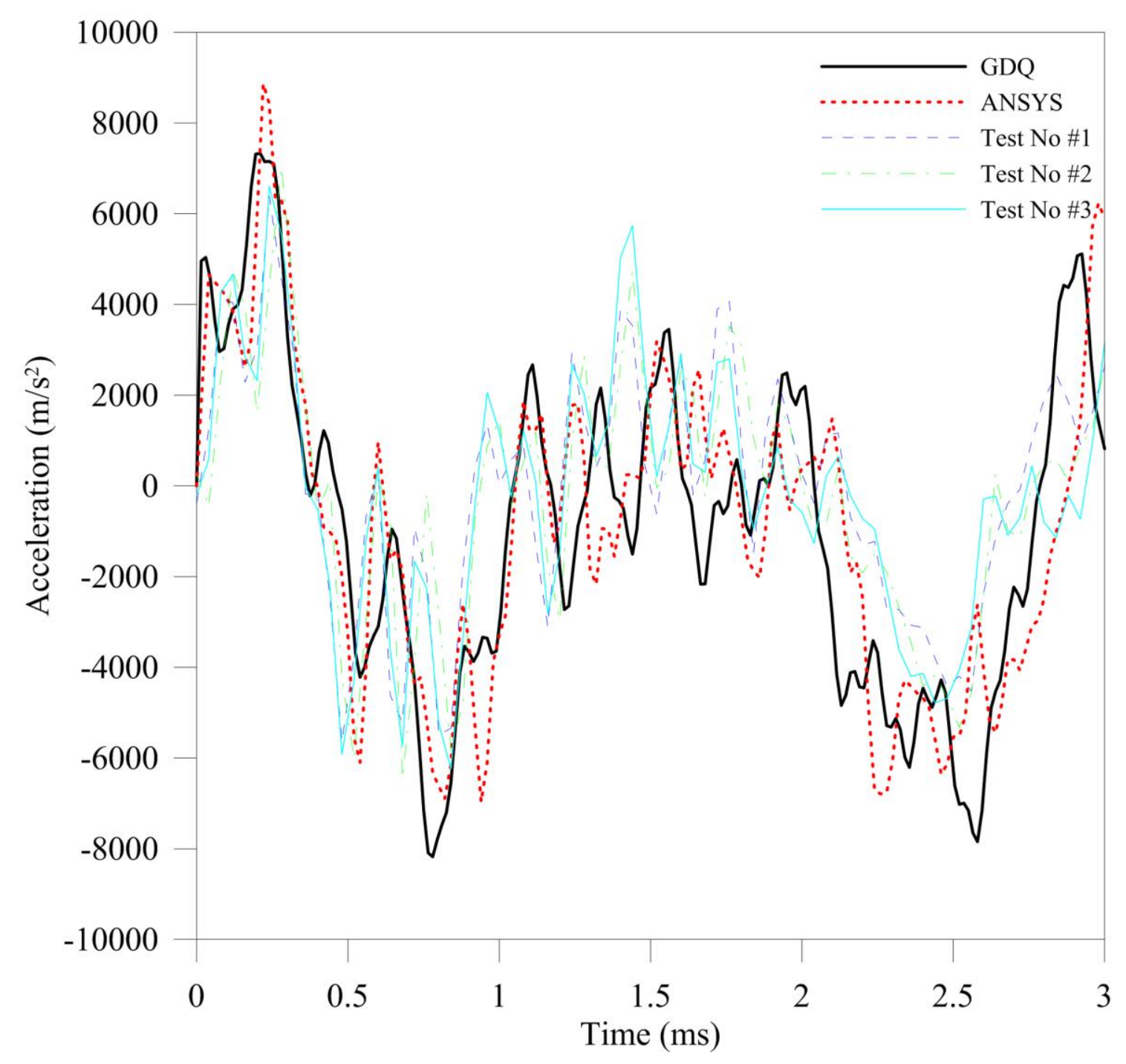

Fig 23. 


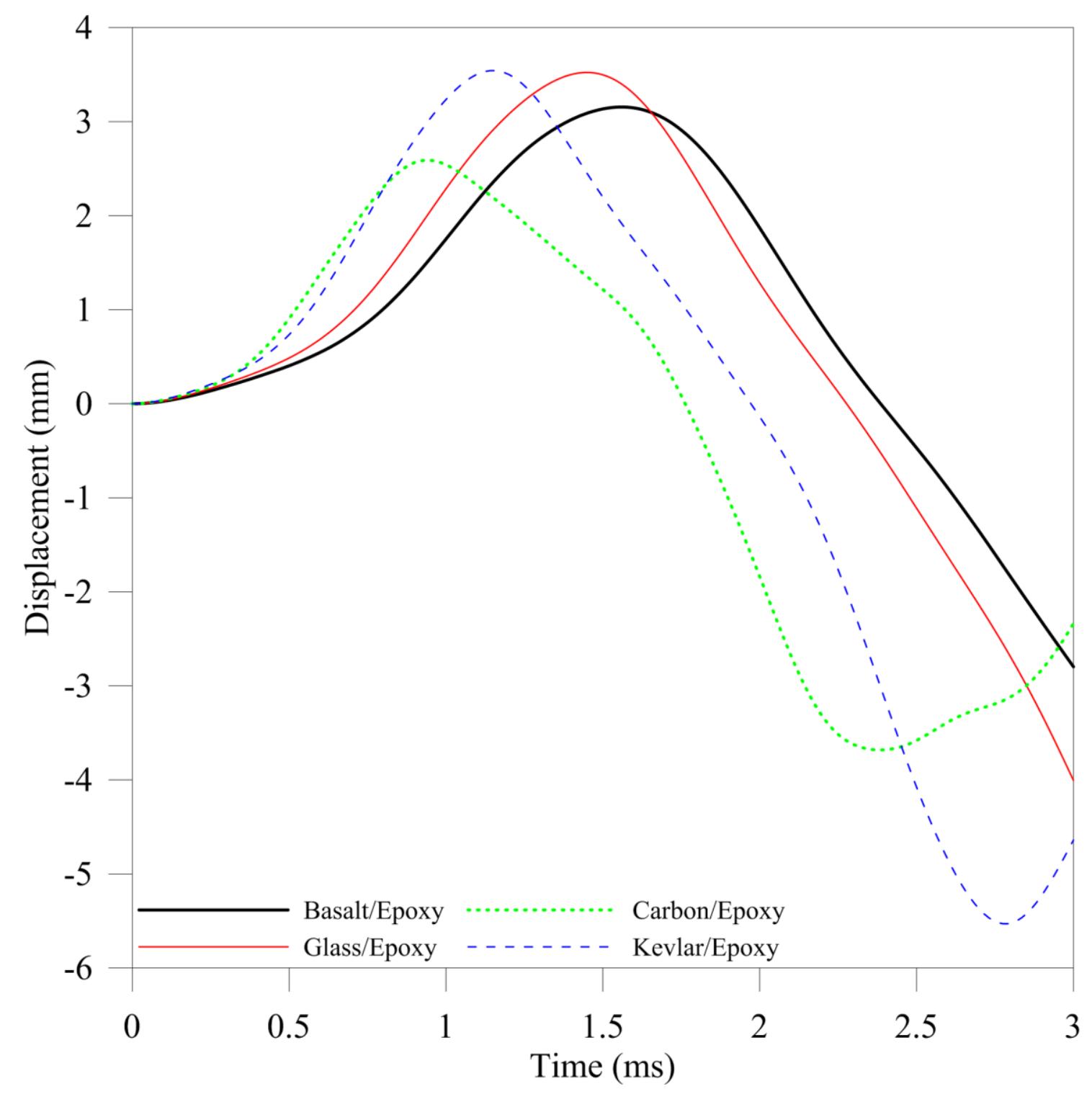

Fig 24. 


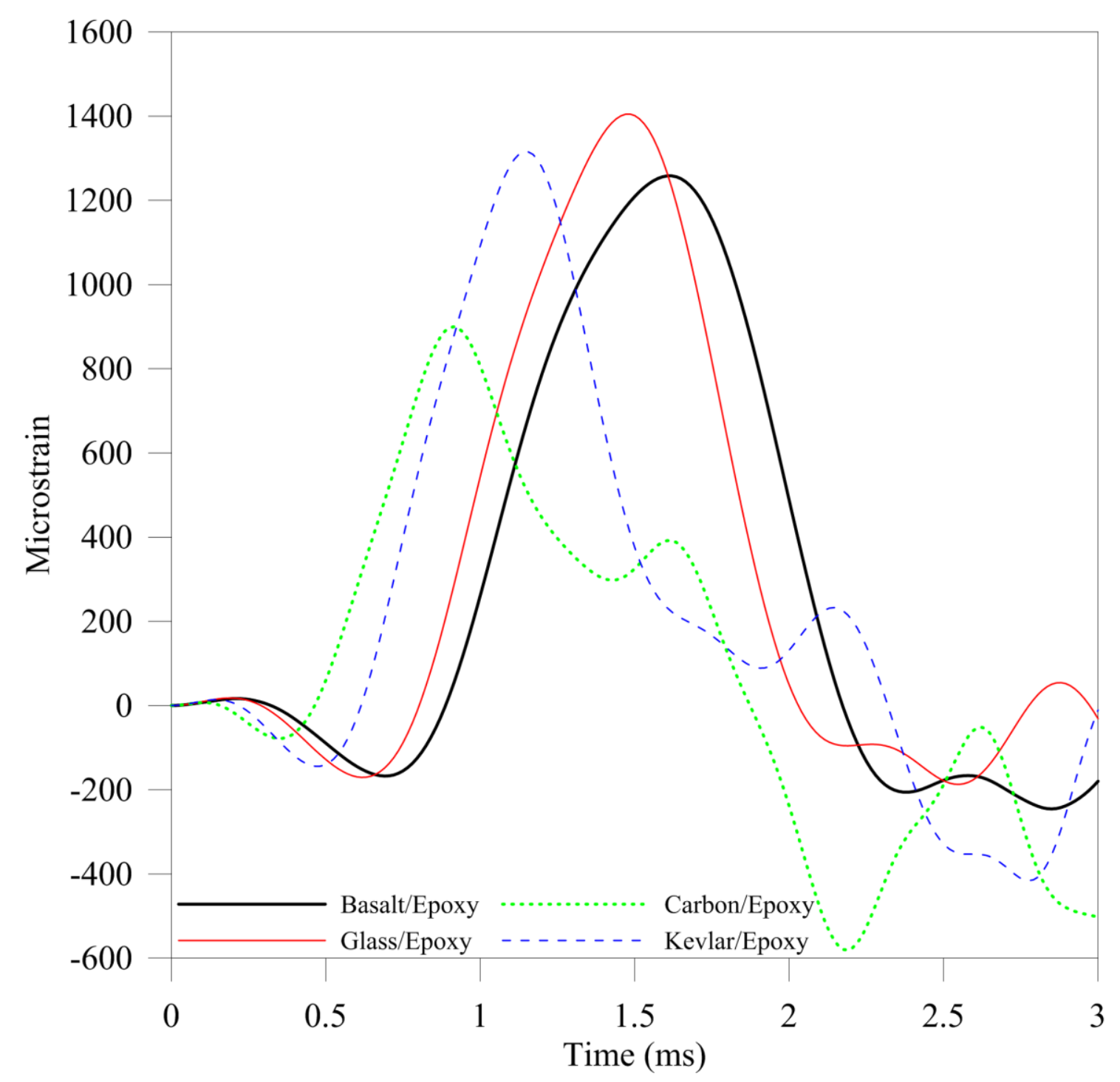

Fig 25. 


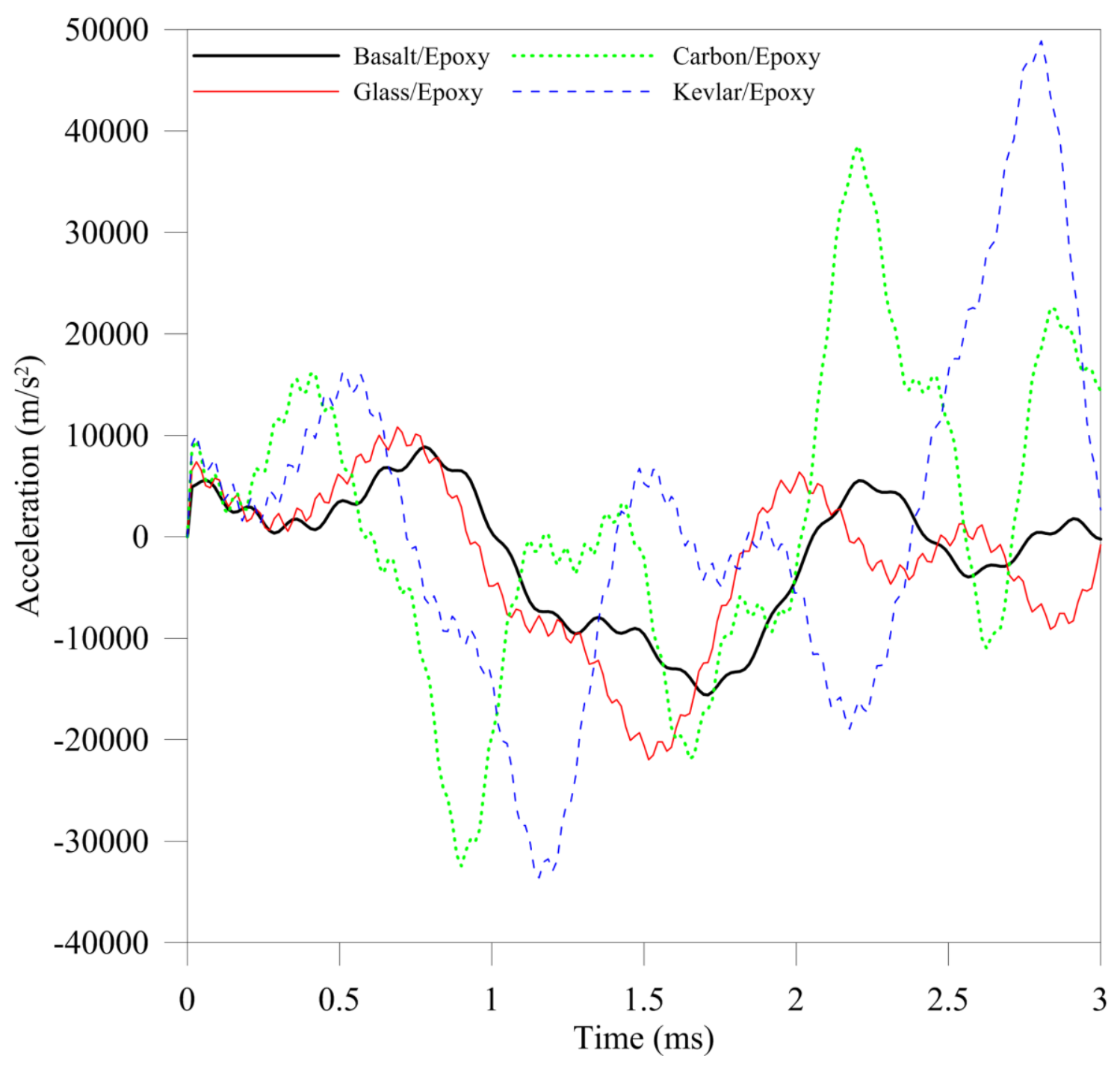

Fig 26. 